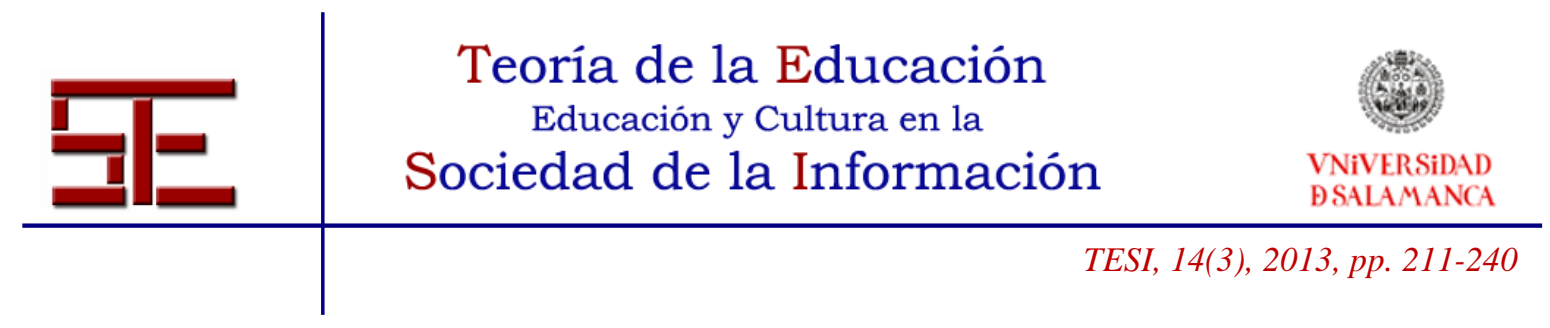

\title{
LOS RETOS EDUCATIVOS EN LA SOCIEDAD DEL CONOCIMIENTO. APROXIMACIÓN A LAS APORTACIONES DESDE EL ÁMBITO DE LA EDUCACIÓN MUSICAL
}

Resumen: Saber música, enseñar música y educar con la música son acciones que no significan lo mismo. En este trabajo, la música se aborda como un problema de educación, ya que la experiencia y la expresión artística son susceptibles de educación y la música es una de estas artes. Hay un problema pedagógico que nace de la práctica de la educación artística y del conocimiento de la educación que hace posible el estudio del ámbito musical como objeto y como meta de educación. La educación musical es, primariamente, como cualquier otra área de experiencia educativa, finalidad educativa orientada al uso y construcción de experiencia musical para construirse a uno mismo y saber elegir un proyecto personal de vida. En los apartados de este trabajo se pretende hacer una síntesis de cuál debe ser el papel de la educación musical en la sociedad del conocimiento desde una mirada pedagógica. Actualmente ya no son suficientes los contenidos básicos de enseñanza que el sistema educativo ha perpetuado, el nuevo entorno demanda nuevas competencias que van más allá de la acumulación de conocimientos y deben permitirnos convertir la información en conocimiento y este en saber.

Palabras clave: educación artística, educación musical, educación por la música, sociedad del conocimiento, ámbitos de educación.

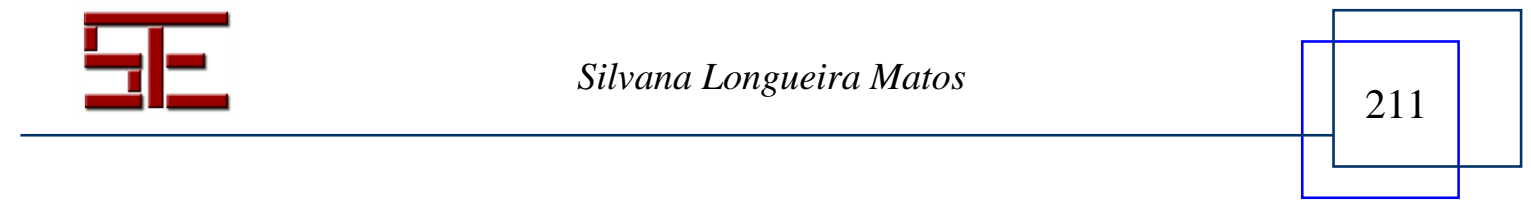




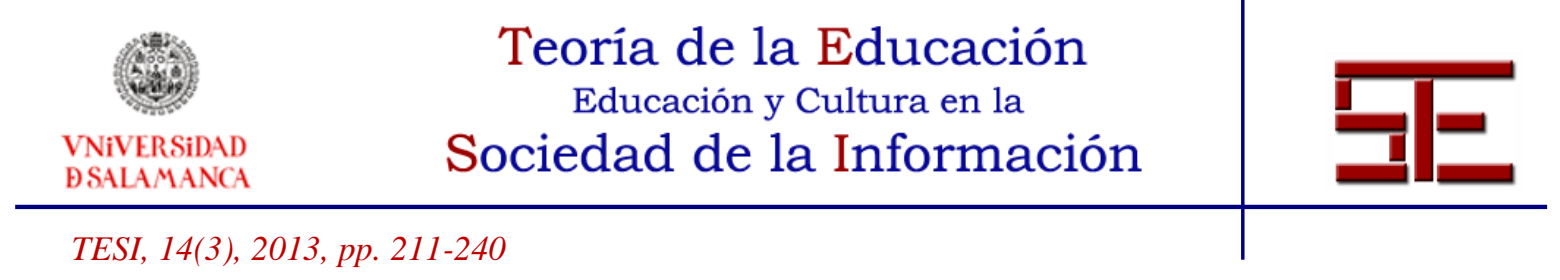

\title{
THE EDUCATIONAL CHALLENGES IN THE KNOWLEDGE SOCIETY. APPROACH TO THE CONTRIBUTIONS FROM THE FIELD OF MUSIC EDUCATION
}

\begin{abstract}
Know music, teaching music and educate with the music are actions that are not the same. In this work, the music is approached as a problem of education, as the experience and the artistic expression are susceptible to education and music is one of these arts. There is a pedagogical problem that arises from the practice of the art education and the knowledge of education that makes possible the study of the music field as an object and as a goal of education. The music education is primarily, like any other area of educational experience, educational purpose orientated to used and construction of musical experience to build yourself and know how to choose a personal project of life. In the sections of this paper aims to summarize what should be the role of music education in the knowledge society from a pedagogical view. Currently are not enough the basic content of teaching that the education system has perpetuated, the new environment requires new competences that go beyond the accumulation of knowledge and should allow us to turn information in knowledge and this in know.
\end{abstract}

Key words: art education, music education, education through music, knowledge society, education fields.

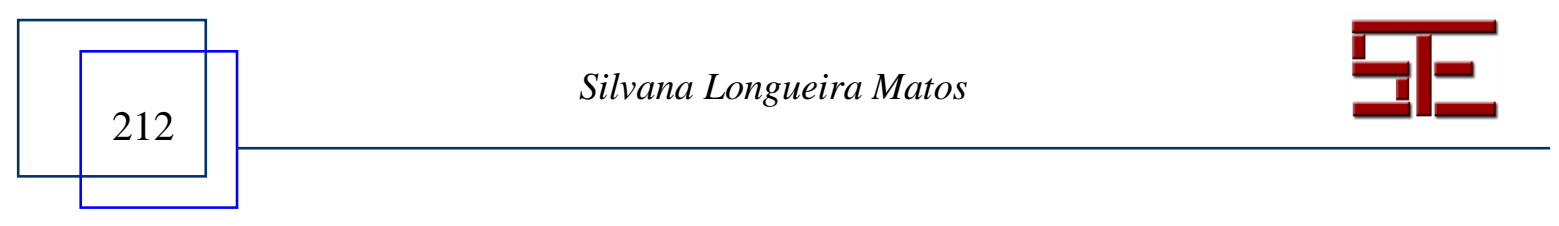




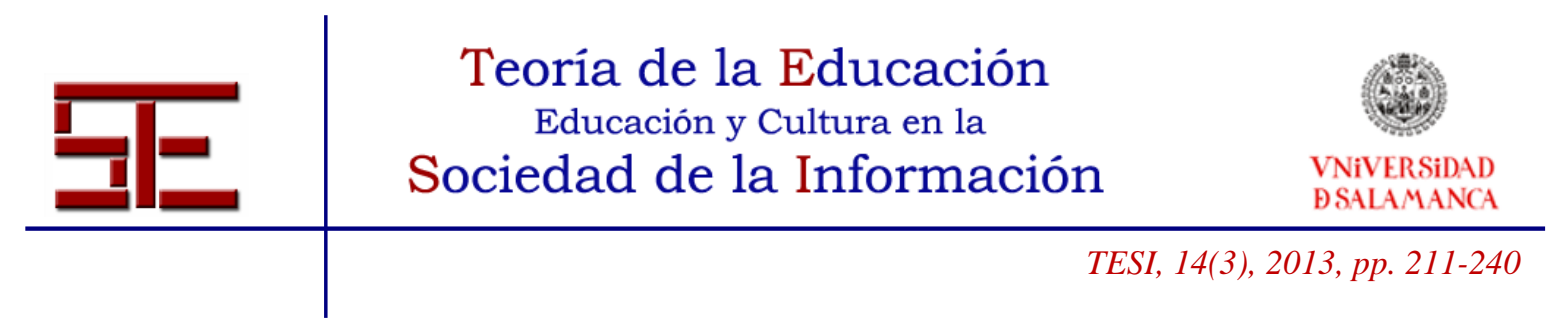

\section{LOS RETOS EDUCATIVOS EN LA SOCIEDAD DEL CONOCIMIENTO. APROXIMACIÓN A LAS APORTACIONES DESDE EL ÁMBITO DE LA EDUCACIÓN MUSICAL}

Fecha de recepción: 15/06/2013; fecha de aceptación: 11/07/2013; fecha de publicación: 30/11/2013

Silvana Longueira Matos

silvana.longueira@udc.es

Universidade da Coruña

\section{INTRODUCCIÓN}

Saber música, enseñar música y educar con la música son acciones que no significan lo mismo. En este trabajo, la música se aborda como un problema de educación, ya que la experiencia y la expresión artística son susceptibles de educación y la música es una de las artes. Hay un problema pedagógico que nace de la práctica de la educación artística y del conocimiento de la educación que hace posible el estudio del ámbito musical como objeto y como meta de educación. La educación musical es, primariamente, como cualquier otra área de experiencia educativa, finalidad educativa orientada al uso y construcción de experiencia musical para construirse a uno mismo y saber elegir un proyecto personal de vida.

Educación musical es, por denominación, primero educación, y todo lo que se proponga para esta afecta y debe ser considerado para el ámbito específico "musical". Hoy podemos afirmar que las artes son un problema de educación, porque la experiencia y la expresión artística son susceptibles de educación. En el ámbito de la educación artística, la tradición más depurada no es ajena a la distinción disciplinar de tres modos de abordar la relación entre educación y artes: una hace referencia al concepto de educación artística, otra se preocupa especialmente por el lugar de las artes en la enseñanza, es decir, del currículo escolar educativo y la tercera se centra en la importancia del conocimiento de la educación y su necesidad para la educación artística (Touriñán, 2010).

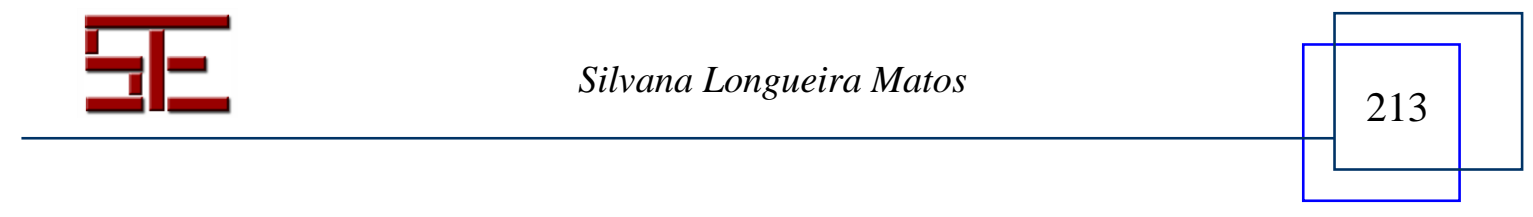




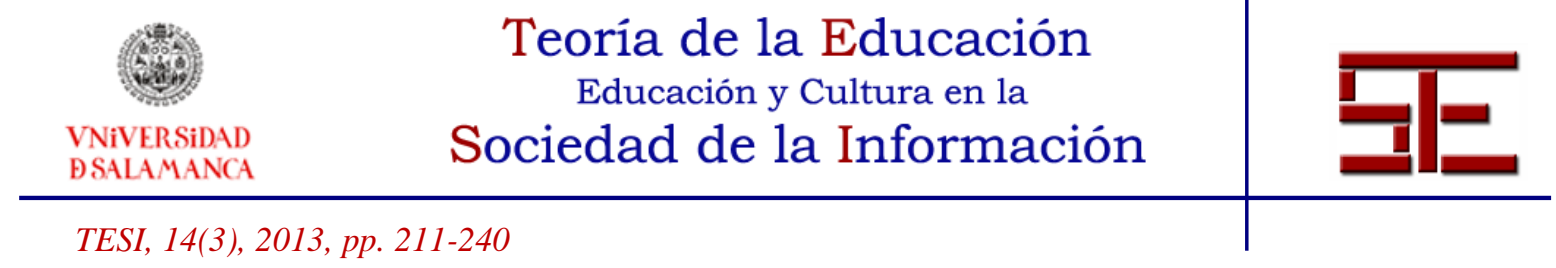

Figura 1. Ámbito disciplinar de la Educación Artística como parte de la Educación como disciplina

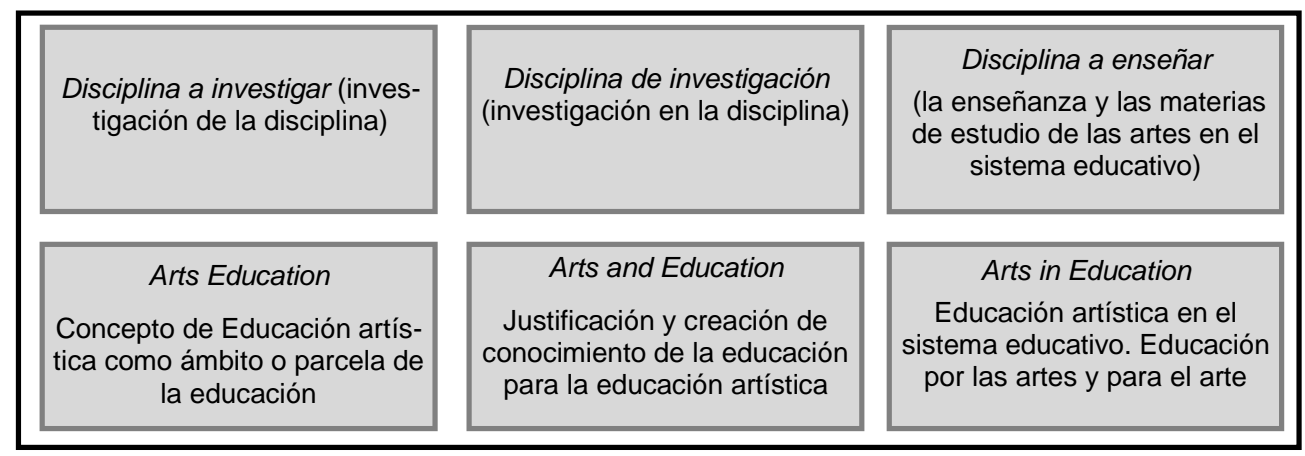

Fuente: Touriñán 2010, 7

En los siguientes apartados se pretende hacer una síntesis de cuál debe ser el papel de la educación musical en la sociedad del conocimiento desde una mirada pedagógica. En nuestros días, junto con la globalización, hay cuatro ideas que han modificado el contexto de trabajo y de pensamiento (Touriñán, 2010; SEP, 2004): la idea de Tercer Sector (Sociedad Civil, sector no lucrativo), la idea de Tercer Entorno (la sociedad-red), la idea de Mundialización y la idea de Tercera o Cuarta Vía. Todo ello, sumado al alcance transnacional de las acciones globales y la glocalización, ha generado nuevas formas de comunicación y relación, así como nuevas capacidades y competencias necesarias (Ayuste, Gros y Valdivieso, 2012). La educación no es ajena a estos cambios, hoy más que nunca, la educación general debe proporcionar las herramientas para adquirir dichas capacidades, competencias y valores necesarios para poder desarrollarnos en un mundo en permanente cambio y con ingente información. Así mismo, la educación general debe garantizar la igualdad de oportunidades. Ya no son suficientes los contenidos básicos de enseñanza que el sistema educativo ha perpetuado, el nuevo entorno demanda nuevas competencias que van más allá de la acumulación de conocimientos y deben permitirnos convertir la información en conocimiento y este en saber. Cuáles son las aportaciones que la música puede realizar desde la educación general es el objetivo de este trabajo. Para ello abordamos cuatro grandes epígrafes. El primero pretende reflexionar sobre el papel de la música en el desarrollo de nuestra identidad y el sentimiento de pertenencia. Los usos y funciones de la música, la defensa de la identidad cultural a través de documentos internacionales de referencia y la dimensión global de la música completan este bloque.

En el segundo apartado se pretende abordar de forma muy breve cómo ha evolucionado el concepto de lo artístico hasta llegar al significado polivalente de hoy muy relacionado con un mundo abierto e internacionalizado. La tendencia contemplativa que primaba la experiencia estética, casi inalcanzable, convive con movimientos que consideran más

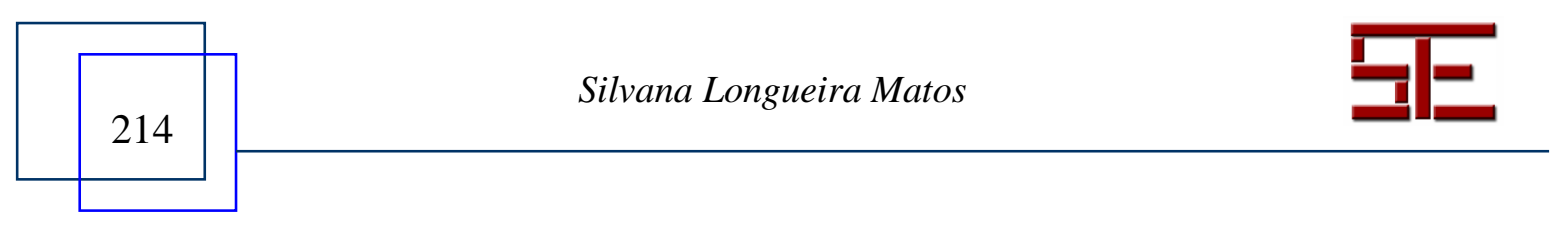




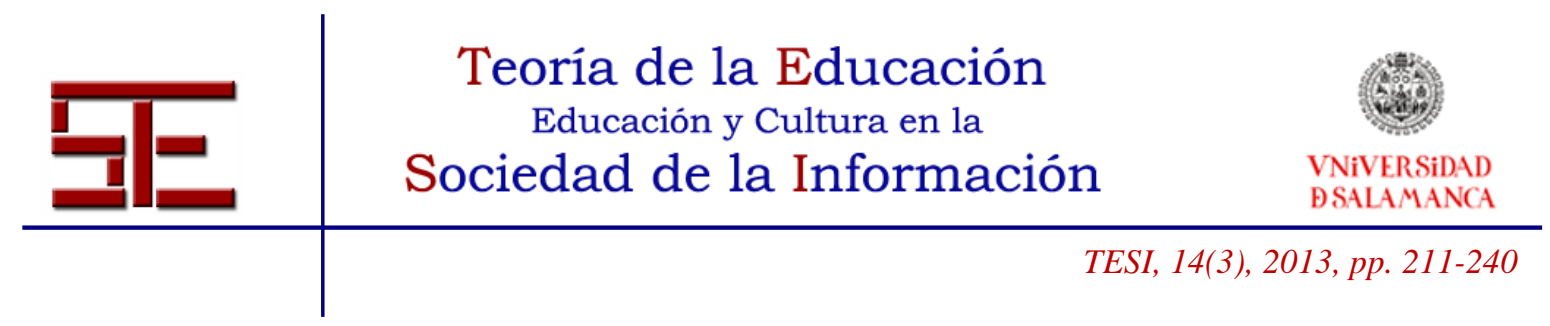

relevante el proceso que el resultado, todo ello con el telón de fondo del mercado global y el creciente interés por las artes como medio de desarrollo individual y comunitario. Todas estas perspectivas tienen influencia sobre la concepción pedagógica de la música.

El tercer bloque se centra en el estado de la educación musical en el sistema educativo. Cinco subepígrafes resumen cómo se encuentra insertada la música en el sistema educativo y muestra la dualidad sobre la que se ha construido la mentalidad pedagógica dominante.

El último bloque pretende esbozar una nueva posibilidad de integración de la música en el sistema educativo, otra forma de entender el valor de las artes y de la música en la educación general, en la educación para todos, que exige un nuevo modo de acometer la cuestión, que exige otra mirada pedagógica (Touriñán y Sáez, 2012). Asumir la diferencia entre educación "por" la música y educación "para" la música, nos obliga a analizar la educación musical como ámbito de intervención pedagógica que debe ser abordado como ámbito general de educación y como ámbito de educación general.

\section{EL PAPEL DEL ARTE EN LA CULTURA: IDENTIDAD Y PERTENENCIA A TRAVÉS DE LA MÚSICA}

En este epígrafe se revisan de forma casi esquemática los usos y funciones más aceptados de la música, que demuestran la consideración hacia el valor comunicativo, cohesionador y socializador de la misma, con las consiguientes implicaciones en la educación general dentro de la sociedad del conocimiento.

La idiosincrasia de las culturas y el interés del patrimonio cultural común, el valor de la cultura en la formación individual y la implicación de las manifestaciones culturales en la cohesión social definen el concepto de identidad cultural en los documentos oficiales de relevancia. En la segunda parte de este apartado revisaremos, grosso modo, algunos de estos documentos, ya que este tipo de declaraciones por parte de instituciones internacionales supone el reconocimiento a la necesidad de formar a los ciudadanos en valores estéticos y artísticos, como parte de lo cultural, para la construcción de experiencia axiológica respecto del sentido de lo social en las personas, individual e institucionalmente consideradas.

La sociedad del conocimiento se construye sobre el concepto de mundo global. Las tecnologías de la información y las comunicaciones, los nuevos límites fronterizos y los mercados mundiales nos empujan a movernos dentro de un concepto amplio de territorio de actuación, dentro de las limitaciones e idiosincrasias que el espacio físico inmediato en el que nos arraigamos nos impone y nos exige. En esta dualidad, el concepto de glocalización cobra cada día más fuerza y más interés. La música no es ajena a este fenómeno, a ello dedicamos un breve apartado final dentro de este epígrafe.

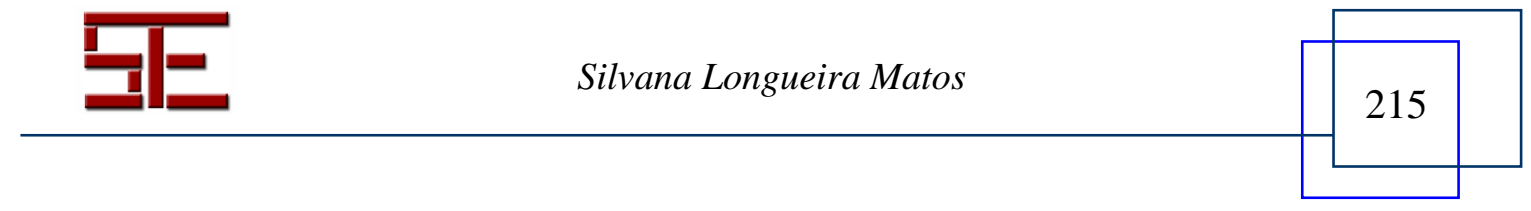




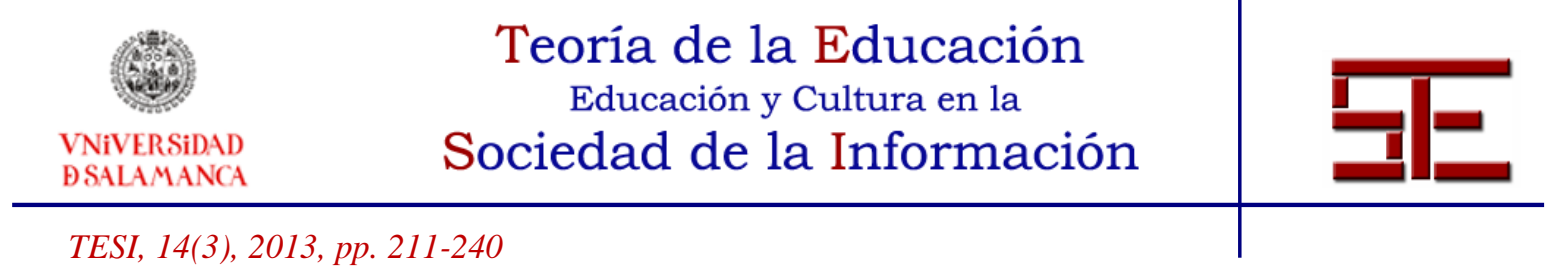

\subsection{Usos y funciones de la música}

El concepto de función en las ciencias sociales comienza a utilizarse en la década de 1950 desde la antropología (Flores, 2008). En el ámbito musical el estudio de referencia, todavía hoy, es The Anthropology of Music elaborado por Merriam y publicado en 1964 sobre los usos y funciones de la música. Este autor proponía diez usos y funciones que han servido de base para trabajos posteriores en la antropología de la música, la etnomusicología, la psicología de la música, la sociología y la educación musical. Para el trabajo que nos ocupa los usos y funciones propuestos por este autor tienen especial relevancia al vincularse a la idiosincrasia de cada cultura y al desarrollo social. La propuesta plantea las siguientes formulaciones (Merriam, 1964):

-Función de expresión emocional: la música está ligada con la emoción y es un vehículo para la expresión de la misma. La expresión musical es un canal que permite la formulación de ideas y emociones no exteriorizadas en el lenguaje cotidiano.

-Función de goce estético: música y estética están asociadas en varias culturas. Es un parámetro que debe observarse tanto desde la perspectiva del autor como del oyente.

-Función de entretenimiento: característica generalizable a todas las culturas, aunque es necesario diferenciar entre entretenimiento "puro" y entretenimiento combinado con otras funciones.

-Función de comunicación: se puntualiza la idea que conforma la música como un lenguaje universal, destacando el poder de la cultura a la que pertenece en la realización de los significados.

-Función de representación simbólica: el autor plantea dudas respecto a que la música funcione simbólicamente en todas las culturas, representando cosas, ideas o comportamientos.

-Función de respuesta física: a pesar de que las respuestas que provoca la música están delimitadas por convenciones culturales, parece tener una relevancia generalizada en las diferentes culturas.

-Función de refuerzo de la conformidad a las normas sociales: diferentes expresiones musicales instruyen sobre lo adecuado e inadecuado, ocupando un papel relevante en numerosas culturas.

-Función de refuerzo de instituciones sociales y ritos religiosos: determinadas canciones promovidas por instituciones sociales resaltan lo que es adecuado y lo que no, con la intención de validación.

-Función de contribución a la continuidad y estabilidad de una cultura: como una consecuencia del cumplimiento de todas las anteriores, la música se reconoce como una actividad en la que se sintetiza la expresión de valores y ayuda a la continuidad.

-Función de contribución a la integración de la sociedad: al proporcionar un núcleo de solidaridad en torno al cual se congregan los miembros de una sociedad, la música realiza una función integradora.

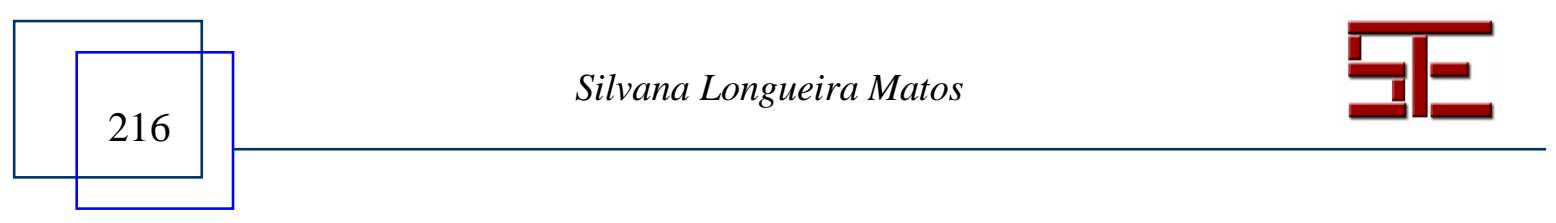




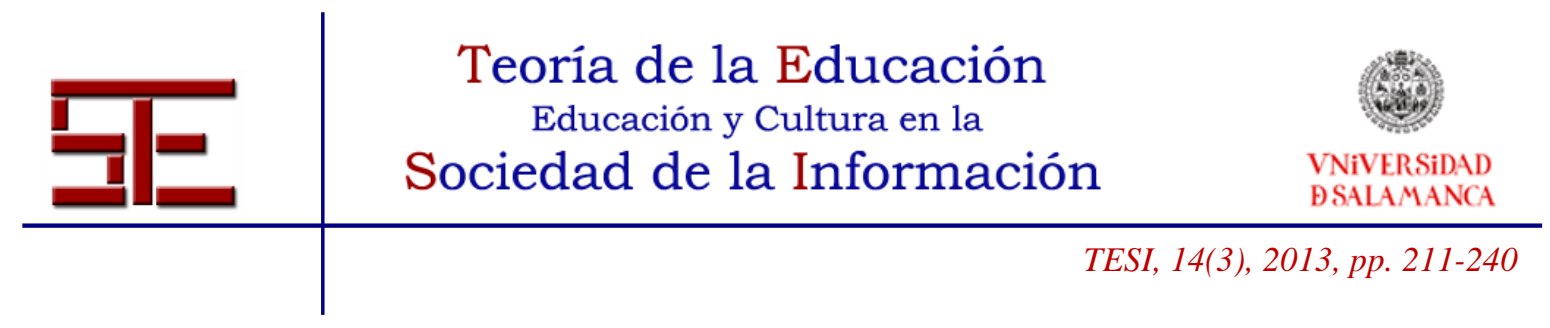

La propuesta de Merriam ha generado diversos estudios al contextualizar las funciones en una cultura o aplicarlas a una disciplina concreta. Algunos resultados han permitido distinguir una sociedad de otra atendiendo a las funciones dominantes de la música: en culturas donde la música ocupa un elevado status, suele utilizarse como medio de expresión emocional; la función de entretenimiento es baja en sociedades tribales; así mismo, la función de validación de rituales es más importante en las culturas rurales y más baja en culturas urbanas (Flores, 2008). La cuestión de las funciones desde la educación musical fue abordada por Campbell (1998), observando su asunción en niños, poniendo de relevancia la respuesta física y dejando a un lado el simbolismo. Desde la psicología Hargreaves y North (1999) desarrollaron las funciones desde el individuo, añadiendo la función de identidad personal que se perfila como una de las más importantes en el estudio, junto a la interpersonal y el comportamiento. En todo caso, todos los trabajos ponen de relevancia la importancia que tiene la música como elemento comunicativo, cohesionador y socializador. Podríamos añadir aquí un nuevo uso que utilizaría el poder de los otros ya definidos para realizarse, el uso educativo de la música, destacando el potencial para el desarrollo de contextos de convivencia y para la formación de ciudadanos responsables.

\subsection{La identidad cultural}

La Unión Europea (UE) considera la cultura como un elemento fundamental en su desarrollo, generando estrategias que permitan la preservación de las identidades de los Estado y las regiones con una conciencia común. En este sentido el Tratado de funcionamiento de la UE dedica su Título XIII (artículo 167) a la cultura, destacando el respeto de la diversidad nacional y regional de los Estados miembros y poniendo de relieve el patrimonio cultural común. Así mismo en el Título XII, dedicado a la educación, formación profesional, juventud y deporte, se recoge que "la Unión contribuirá al desarrollo de una educación de calidad fomentando la cooperación entre los Estados miembros y, si fuere necesario, apoyando y completando la acción de éstos en el pleno respeto de sus responsabilidades en cuanto a los contenidos de la enseñanza y a la organización del sistema educativo, así como de su diversidad cultural y lingüística" (art. 165).

Por su parte, la Declaración sobre el Regionalismo en Europa hace hincapié en la identificación que los ciudadanos establecen con sus regiones a través de lazos históricos, lingüísticos, culturales, sociales, económicos y geográficos, cuya variedad constituye una riqueza inagotable (Asamblea de las Regiones de Europa, 1996).

A su vez, en la Declaración de México sobre políticas culturales se afirma que:

“(...) la cultura da al hombre la capacidad de reflexionar sobre sí mismo. Es ella la que hace de nosotros seres específicamente humanos, racionales, críticos y éticamente comprometidos. A través de ella discernimos los valores y efectuamos opciones. A través de ella el hombre se

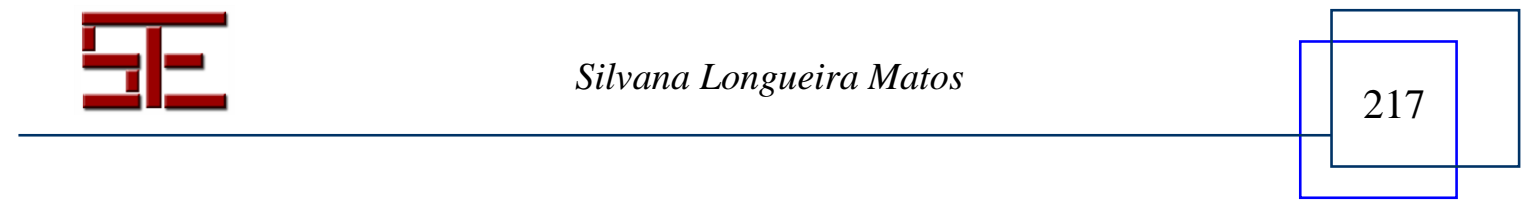




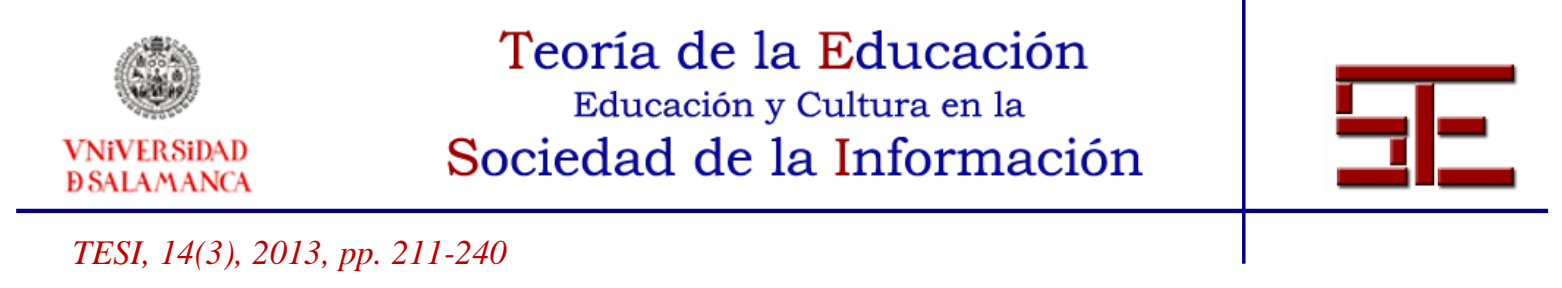

expresa, toma conciencia de sí mismo, se reconoce como un proyecto inacabado, pone en cuestión sus propias realizaciones, busca incansablemente nuevas significaciones, y crea obras que lo transciendan" (UNESCO, 1982).

La Segunda Conferencia Mundial sobre la Educación Artística señala que esta debe desempeñar una función importante en la transformación constructiva de los sistemas educativos, esforzándose por satisfacer las necesidades de los estudiantes en un mundo que se transforma con rapidez. La Agenda de Seúl, derivada de esta Conferencia se organiza en tres grandes metas y la propuesta de estrategias derivadas. Como tercer objetivo se plantea "aplicar los principios y las prácticas de la educación artística para contribuir a la solución de los problemas sociales y culturales del mundo contemporáneo" (UNESCO, 2010). Las estrategias para esta meta se definen en los siguientes términos:

a. Impartir la educación artística para fortalecer la capacidad de creación e innovación de la sociedad.

b. Reconocer y desarrollar las dimensiones de bienestar social y cultural de la educación artística.

c. Apoyar y fortalecer la función de la educación artística en la promoción de la responsabilidad social, la cohesión social, la diversidad cultural y el diálogo intercultural.

d. Fomentar la capacidad de responder a los principales problemas mundiales, desde la paz hasta la sostenibilidad, mediante la educación artística.

El valor de la educación artística como parte de la cultura y como elemento socioidentitario es así reconocido de forma progresiva a través de los múltiples documentos, acuerdos y declaraciones de organismos e instituciones internacionales. Desde un punto de vista antropológico la cultura lo abarca todo y desde el punto de vista estético, el arte, y por inclusión la música, son formas de expresión cultural. La relación entre cultura y música ha sido desarrollada en numerosos trabajos por diferentes autores (Pelinski, 2000; Blacking, 2001; Cruces, 2001; Graeme, 2003). En todo caso, resulta de especial interés para este trabajo el planteamiento de Cruces desde la etnomusicología cuando se refiere a la coherencia sociocultural de la música como una relación con el mundo social entendido como un todo: "pues el universo compartido de los valores sonoros remite, de diversas (y enigmáticas) formas, a otro universo más amplio de valores y experiencias que colabora a construir y recrear de forma decisiva" (Cruces 1998, 46).

\subsection{La música en el proceso glocal}

En las sociedades abiertas occidentales, la ciudadanía y la convivencia se han convertido en ejes fundamentales de la educación, porque representan de manera

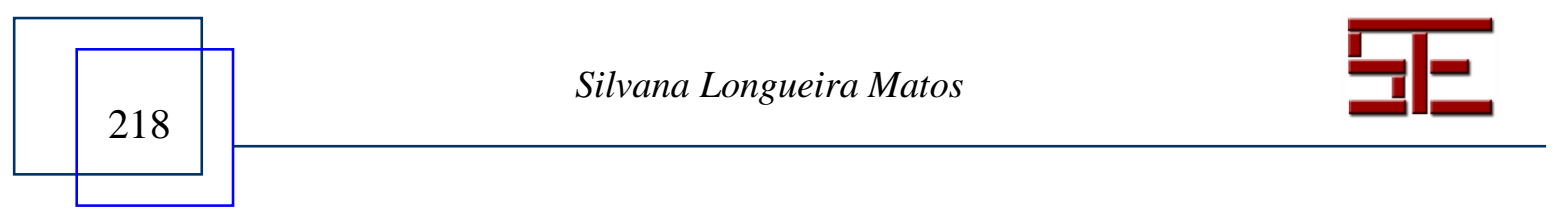




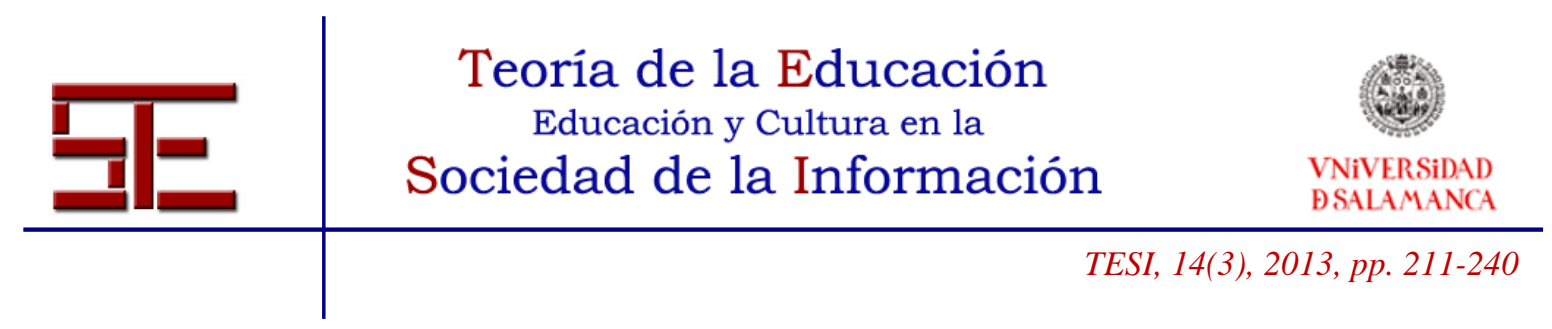

genuina los ámbitos externo e interno de la educación de la responsabilidad con sentido democrático (Touriñán y Longueira, 2009; Touriñán, 2010). El sesgo propio de la mundialización, la civilización científico-técnica, la sociedad de la información, junto con el sentido democrático de las sociedades abiertas que se manifiesta en la participación, la autonomía y el reconocimiento y respeto al otro configuran el nuevo marco de pensamiento que justifica el sentido de la educación en valores en nuestro mundo (SEP, 2004). Este nuevo desafío tiene que asumir en el marco de los derechos culturales las consecuencias de entender la transnacionalidad y la glocalización como condiciones inherentes de los derechos de tercera generación. Y en el marco de estos derechos el juego del desarrollo no está en un equilibrio pactado entre los Estados para conjugar soberanía y subsidiariedad. Estado, Sociedad civil y Mercado son corresponsables del desarrollo mundial (Touriñán, 2008).

En este contexto, la música se representa como un lenguaje universal para la creación de un lenguaje global sin fronteras territoriales ni culturales. A este respecto, Martínez Berriel (2011) añade:

\begin{abstract}
"La música aúna con especial capacidad el valor económico y el espiritual, e incluso intenta, pese a la dificultad que ello entraña, hacerlos compatibles. No olvidemos que el sonido llega donde ni siquiera alcanza la vista y que su poder de unir en la distancia es sumamente eficaz tanto en términos de identidad, en sentido permanente, como de circunstancial identificación colectiva. Por ello, la música es un medio privilegiado para transitar con excelencia las inquietudes humanitarias de la globalización: el dialogo igualitario entre las culturas, la paz mundial y el desarrollo sostenible" (Martínez Berriel 2011, 7).
\end{abstract}

Si bien es cierto que, como se puede observar en el apartado 2.1., dedicado a los usos y funciones de la música, la función comunicativa y simbólica de la música está conformada por la cultura a la que pertenece, el lenguaje sonoro, por su imprecisión conceptual, su carácter espiritual y etéreo y su capacidad de apelar al ámbito afectivo, puede entenderse como un lenguaje universal.

La tradicional consideración de la música como hecho inmaterial y trascendental que la relega a una valoración secundaria en una sociedad que prima lo tangible se debilita ante las cifras que arroja el consumo de la cultura de masas. Las cifras macroeconómicas muestran una actitud favorable de la población hacia la música. Según la Cuenta Satélite de la Cultura en España en el período 2000-2009 la participación en el producto interior bruto (PIB) de las actividades culturales ha supuesto el $3 \%$ y si se tienen en cuenta las actividades vinculadas con la propiedad intelectual, la cifra asciende hasta el 3,9\% (MCU, 2011). Estos datos se ven reforzados por los que aporta la Sociedad General de Autores y Editores (SGAE) sobre el mercado musical juvenil que apuntan a que un 52,2\% de jóvenes entre 15 y 19 años ha comprado al menos un disco en los últimos tres meses. En este mismo rango de edad, el 99,8\% dispone de tecnología para escuchar música y el 99,4 tiene el hábito de hacerlo (SGAE, 2011). Por otro lado, de los 11,7 millones de euros que en 2006 destinamos a

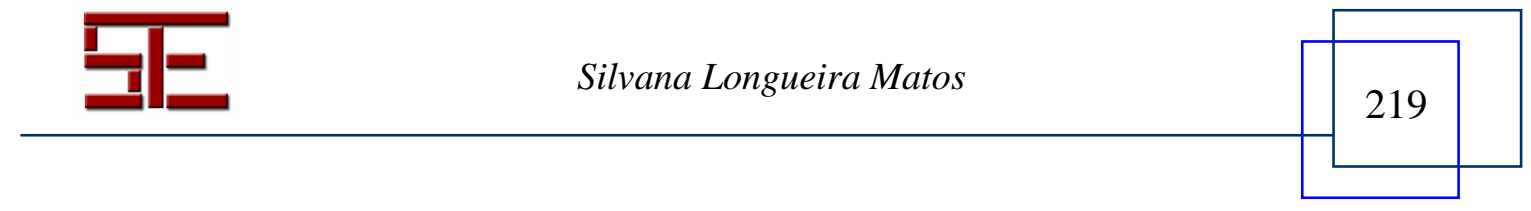




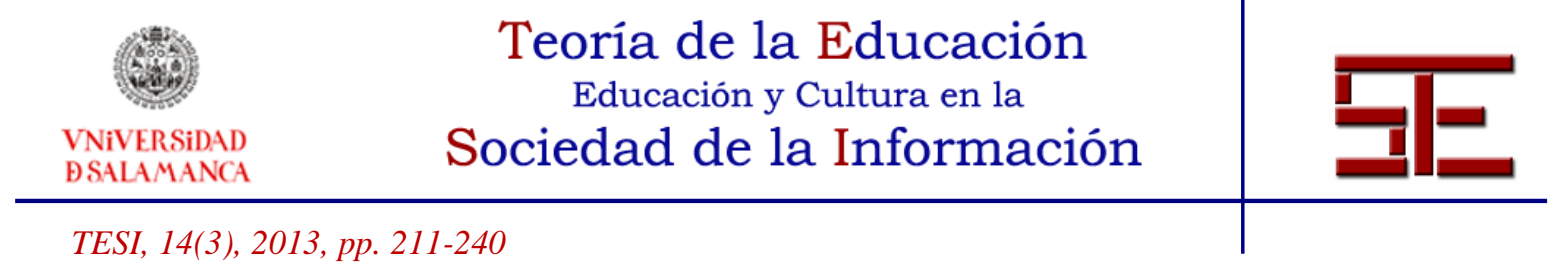

actividades de ocio, un 37,2\% del total se dedicaron a actividades artísticas y de espectáculo (INE, 2008). Al impacto directo de la música en nuestra vida, la unión entre música y tecnologías de la información y las comunicaciones supone una expansión mayor en nuestra cotidianeidad. La publicidad, el cine, la televisión, la radio, los videojuegos, las consolas, los dispositivos de almacenamiento masivo, Internet, expanden y globalizan los contenidos musicales. Según datos del Instituto Nacional de Estadística (INE) el 92,8\% de la población entre 16 y 74 años tiene móvil, porcentaje que asciende hasta un 98\% si limitamos el rango de la muestra a los 16-24 años (INE, 2011), lo cual, con la nueva generación de móviles, abre la vía a la conectividad permanente y al almacenamiento de datos siempre disponible. La mitad de las conexiones a Internet en el último año se realizaron a través de terminales móviles. Además el 89,6\% de los usuarios de la red reconocen que cuando se conectan escuchan o se descargan música (SGAE, 2011).

Estas cifras nos obligan a hacer una doble lectura. En primer lugar demuestran el interés y el hábito de la población por el consumo de cultura y de cultura musical. Hoy no nos imaginamos nuestro entorno sin música. Sin embargo, asistimos al debilitamiento de la utilidad identitaria y nacional de la cultura en el sentido trascendental, que rebaja el interés del Estado por el arte, y a la expansión de la dimensión económica (Martínez Berriel, 2011), en ocasiones camuflada como democratización de la alta cultura, cuando de forma masiva observamos la privatización y explotación del arte por parte de un pequeño grupo de multinacionales. Se abre un nuevo panorama, el de la economía de la cultura que avanza, como la mayoría de las áreas de conocimiento entre los juegos del globalismo, la globalidad y la globalización; la occidentalización, la mundialización y la transnacionalidad; sociedad mundial, sociedad global y producción global. El resultado es la configuración de productos musicales globales (en ocasiones generados por los mercados para estimular el círculo del consumo) frente a una creciente producción de oferta musical configurada en base a las identidades locales y enraizadas en las tradiciones folclóricas. Es la representación en el ámbito musical de la glocalización, comprender las acciones locales en un mundo global.

\section{EL ARTE Y LA EXPRESIÓN ARTÍSTICA: TENDENCIAS DEL ARTE Y DE LO ARTÍSTICO}

\subsection{Nuevos paradigmas en la consideración del objeto artístico}

En la progresiva transformación del arte como instrumento de creación, actualmente predomina la función social sobre la función estética del arte, que no supondría otra intención que la expresión con sentido estético, utilizando los diversos soportes sensibles: el lenguaje, los sonidos o las formas visuales (Ors, 1980; Jiménez, 2002; Touriñán, 2010). Es así que “(...) en la Historia del pensamiento artístico hemos pasado

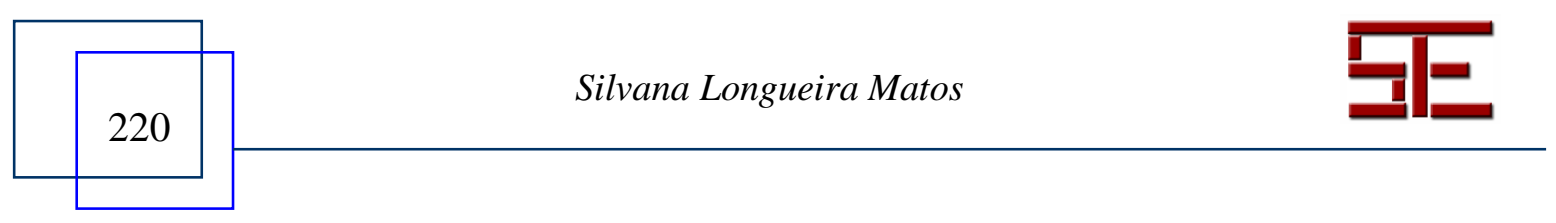




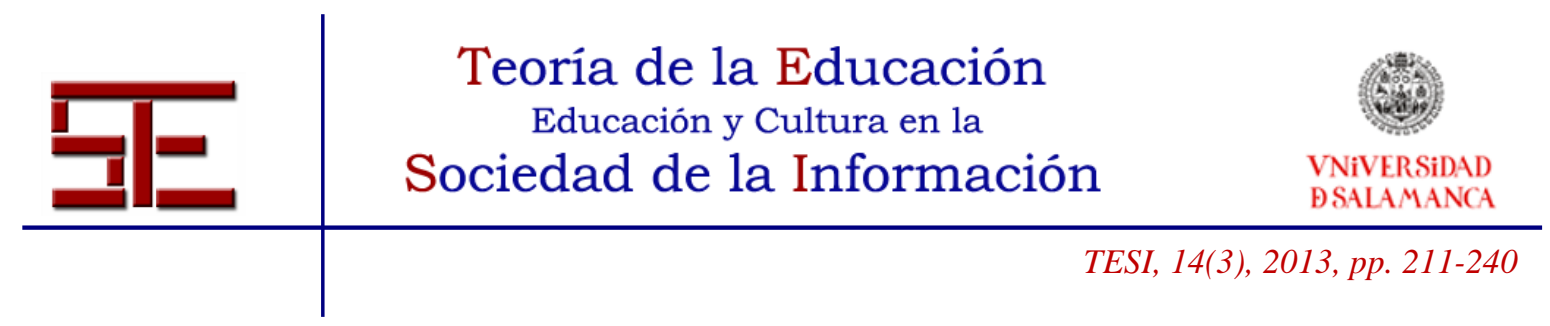

del arte como testigo de la historia de los hombres, a la deshumanización del arte. La tendencia es primar en el arte los objetos sobre el hombre y mantener la sorpresa, lo inesperado, lo asombroso como nuevo postulado estético y marca de la creación original" (Touriñán 2010, 93). La tendencia contemplativa basada en la expresión estética deja paso a nuevas vías que pretenden imponerse y limitar lo artístico a su paradigma, predeterminando otras manifestaciones como antiguas o inadecuadas. Son mentalidades que tienen una fuerte influencia en la educación artística. Estas vías emergentes, desde el punto de vista del contenido, pueden esbozarse en las siguientes tendencias (Marchán, 1994; Eisner, 2002; Jiménez, 2002, Touriñán, 2010):

-Rechazo de la idea del arte "universal" y "eterno", en función del valor y la funcionalidad que las diferentes culturas imprimen al arte.

-Desdibujar la asociación secular de la obra de arte y del objeto artístico con el "hacer", vinculado al sentido institucionalizado del arte. El mundo avanza, también en el arte, hacia el reconocimiento pleno de la diversidad estética y cultural.

-Unión entre arte y técnica debido al impacto de las nuevas tecnologías en el mundo digital y en la sociedad del conocimiento.

-Producción de mundos posibles, alternativa al mundo material existente.

-Desacralización del arte, ligada a la idea de desmaterialización. En este caso se sustituye el sentido de pieza única original por el de reproducción técnica del objeto artístico, dando lugar a la sustitución de la presencia irrepetible por la presencia masiva característica de la sociedad de masas, con las múltiples posibilidades de distorsión, alteración y fragmentación del original en virtud de las necesidades y exigencias de los usuarios.

\subsection{Educación artística: experiencia vs. resultado}

Diversos autores han señalado la importancia del proceso artístico frente a la relativa trascendencia del objeto artístico (Dewey, 1934; Merriam, 1964 y 2008; Small, 1989; Finnegan, 1998; Cruces, 1998 y 2001). Al examinar las implicaciones sociales de las artes y entre ellas de la música, Small plantea que el arte puede revelarnos modos nuevos de percepción y sentimiento, que nos lleven más allá de los usos habituales. Así cree que son capaces de hacernos tomar conciencia de posibles estéticas e incluso sociedades alternativas (Small, 1989). Se pone de manifiesto la idea de que el arte es algo más que la producción de objetos bellos o expresivos para que otros los contemplen y admiren.

Para Small el arte es esencialmente un proceso, a través del cual exploramos nuestro medio, interior y exterior, aprendiendo a vivir en él. El artista ordena sus percepciones y hace un modelo de la realidad inmediata y potencial, ayudando a otros a hacer lo mismo. La experiencia, como hecho irrepetible, se ensalza como instrumento esencial del arte. Los conocimientos artísticos son experiencia, vivencia, estructuración y

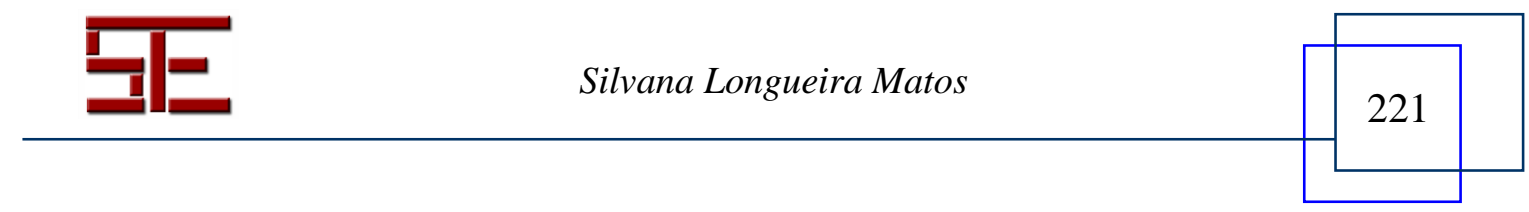




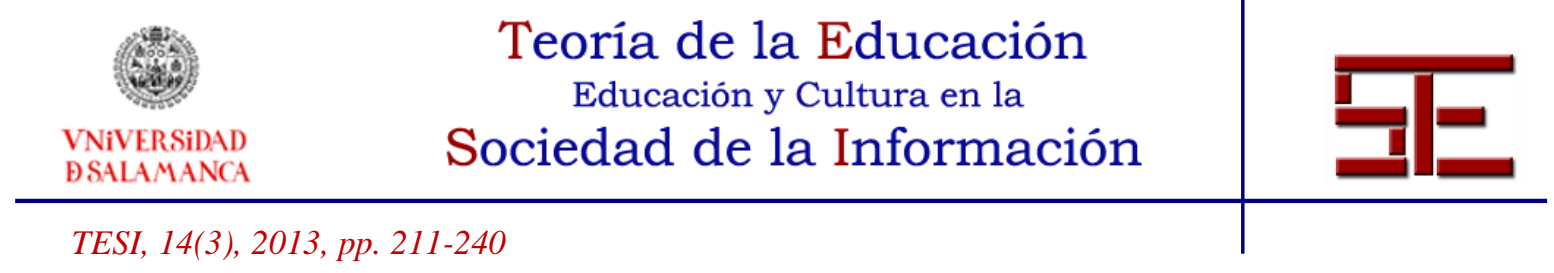

ordenamiento del sentimiento y de la percepción. El potencial de las artes reside en su capacidad de penetrar en ámbitos de la actividad humana que la ciencia es incapaz de tocar. No obstante, "hoy tenemos más conocimiento de la música que nunca, sin embargo, nuestra vivencia de ella está sumamente diluida por el conocimiento de los expertos" (Small 1989, 15).

En este sentido Finnegan destaca la función indispensable que la ejecución musical y la danza cumplen en ciclos personales y públicos, así como en actividades sociales. Las actividades musicales de los distintos exponentes de una cultura se hallan entrelazadas en un contexto general de bienestar mutuo. La involucración personal en la música, en su interpretación, en la creatividad artística genera un sentido de identidad y de valor, de control social y de integración. Esta autora plantea la comprensión del arte en dos planos extremos. Por un lado, el pensamiento convencional ensalza el ideal de individuo genial, independiente de la sociedad que le rodea y que se sitúa por encima de ella: se pone énfasis en la veneración al arte cultivado como algo autónomo en sí mismo y dotado de una existencia fuera de las convenciones sociales y culturales al uso y en el "gran hombre" como primer motor, fundamentado en presuposiciones egocéntricas y evolucionistas (Finnegan, 1998). En el plano extremo, la música es ejecutada por personas en contextos sociales guiados más por convenciones de naturaleza cultural que por un supuesto genio individual, asocial. Una forma de hacer frente a esta dicotomía es centrarse en los procesos activos más que en las obras musicales como tales o sus exponentes individuales, en el producto. Se plantea así un desafío a la reducción de la música como obra musical, cuya última realidad reposa en la partitura, en el texto, despreciando las tendencias de otros estilos más orientadas a la performance. Todo fenómeno artístico es en algún sentido único y, al mismo tiempo, está esencialmente interrelacionado con otras actividades y experiencias de la cultura.

Por su parte, John Blacking ve la música como una modalidad primaria a través de la cual los individuos se expresan y crean sociabilidad humana, encontrando en el

\footnotetext{
“corazón de toda interacción social efectiva (y afectiva) alguna clase de relación de afinación (tuning-in), cuyo modelo ideal es la situación de hacer música juntos. La inteligencia musical es una inteligencia social que permite a la gente organizar sus cuerpos de formas mutuamente agradables e inteligibles, sin necesidad de racionalizar, probar o fijar las experiencias. Parece que los individuos tienen la capacidad de imprimir un sentido musical al mundo, y que pueden, a través de ciertos tipos de ejecución y afinación con otros, formar estructuras de cognición y afecto culturales y sociales" (Blacking 1991, 68-69; Finnegan 2007, 30).
}

A su vez, Cruces al intentar responder a la cuestión de cómo contribuye la música a dar coherencia, consistencia y espesor a nuestra experiencia del mundo social plantea un nuevo elemento a tener en cuenta respecto a la percepción social del arte. Propone centrar la atención en las prácticas musicales en la escucha más que en el sonido, en la actividad que el oído desarrolla en torno a lo que oye. "La frecuente confusión de estos dos aspectos diferenciados del hecho musical -el sonido en tanto que señal acústica y el

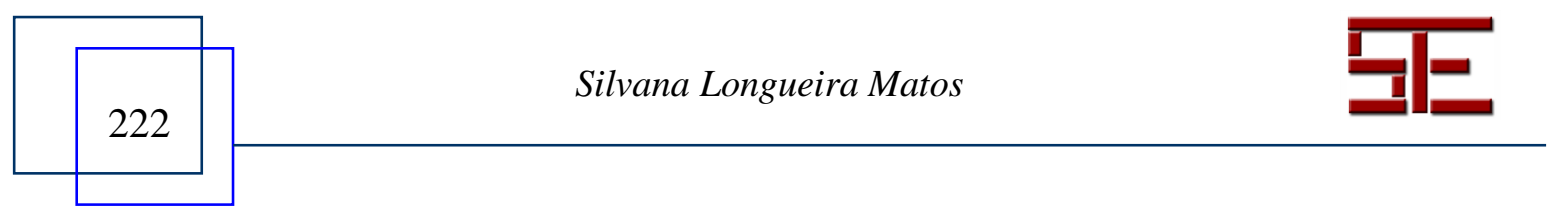




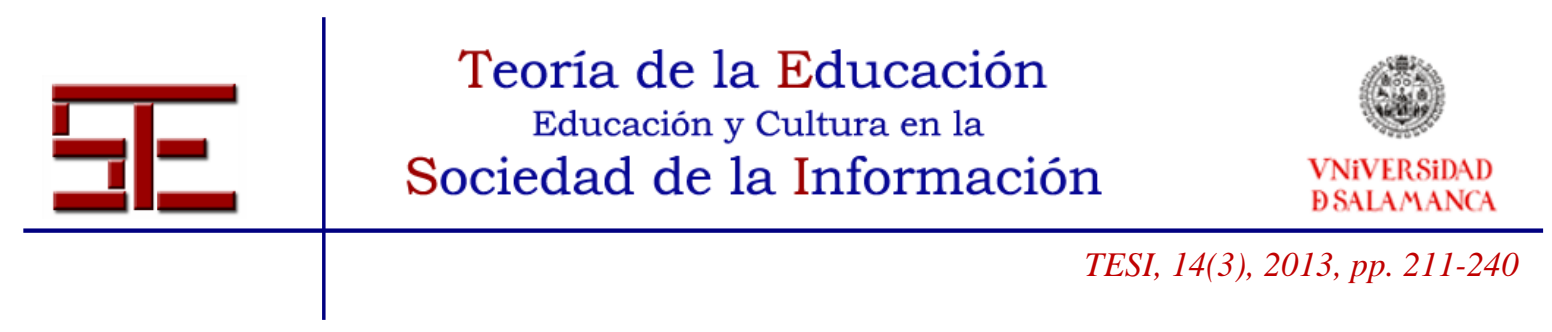

sonido en tanto que fuente cultural de percepciones, sensaciones y conceptos-, ha significado históricamente una limitación para llegar a comprender la gran viabilidad y flexibilidad de los sistemas musicales humanos" (Cruces 1998, 34).

Esto ha impedido prestar atención a las diversas maneras y disposiciones de escuchar y ha llevado a analizar la música de otros como meros patrones de señal acústica, como objetos, más que en analizar lo que sus usuarios oyen realmente. Por ello Cruces, en el trabajo ya citado, plantea la relevancia cognitiva como el elemento jerarquizador y de gobierno de los modos de escucha, así como el valor que estos conceden a cada parámetro y a la relación entre ellos. Oír, escuchar, entender y comprender son los sucesivos niveles de escucha.

Hoy seguimos usando el arte para establecer un estado cultural superior, en contraposición a una cultura nativa y espontánea, y un gran número de docentes siguen transmitiendo este modelo en sus aulas. A su vez se ha generado un mercado internacional impersonal donde las obras de arte pierden su estado vernáculo generando un abismo entre el productor y el consumidor, entre la experiencia ordinaria y la experiencia estética, enfatizando el carácter meramente contemplativo de lo estético. Dewey ya reivindicaba recobrar la continuidad de la experiencia estética con los procesos normales de la vida frente a esta segregación. "La dificultad respecto a las teorías existentes es que parten de una separación ya hecha, o de una concepción del arte que lo "espiritualiza" desconectándolo de los objetos de la experiencia concreta" (Dewey 1934, 12). Las ideas que colocan el arte en un pedestal remoto, penetran tan sutilmente y están tan extendidas, que se aceptan como naturales. La separación del arte de los objetos y escenas de la experiencia ordinaria alejan a los grupos sociales mayoritarios. Cuando determinados objetos son reconocidos como obras de arte por los grupos que arbitran los mercados culturales, se revelan insustanciales a la mayoría por su lejanía.

Además Dewey plantea una segunda apreciación, que reconoce la acción como elemento diferenciador. "Allá donde el hombre esté más implicado en intensificar la vida en vez de meramente vivirla, podremos hablar de un comportamiento estético" (Claramonte 2008, XVI). De nuevo, encontramos la confianza en el arte como medio para hacernos más inteligentes, más sensibles y preparados a través de la experiencia artística: "una obra de arte sólo tiene rango estético cuando la obra llega a ser la experiencia de un ser humano" (Dewey 2008, 4). El arte puede aportar la sensibilidad de relaciones, de modos de relación, que aún no han sido condicionados por las instituciones. Retomando el significado del ars latina y la téchne griega, este autor escribe:

"El mecánico inteligente, comprometido con su trabajo, interesado en hacerlo bien y que encuentra satisfacción en su labor manual, tratando con afecto genuino sus materiales y herramientas, está comprometido artísticamente. La diferencia entre tal trabajador y el chapucero inepto y descuidado, es tan grande en el taller como lo es en el estudio. Con frecuencia el producto no atrae el sentido estético de los que lo usan" (Dewey 2008, 6).

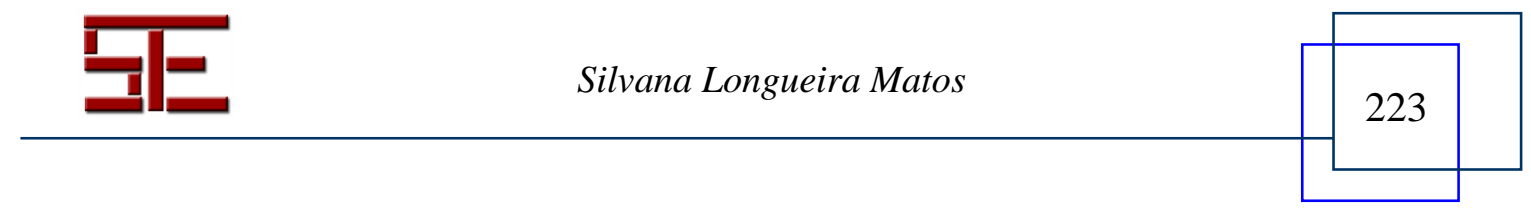




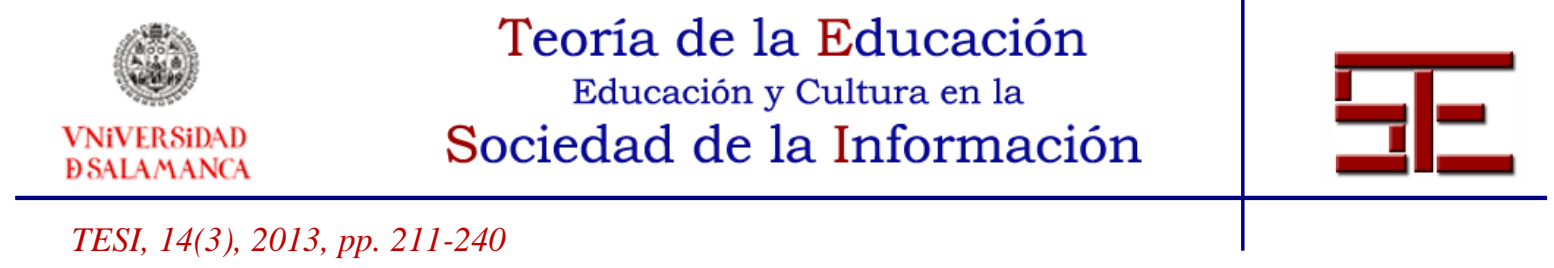

Los utensilios domésticos, mantos, esteras, jarros, arcos, códices, etc. que hoy ocupan nuestros museos, eran medios para exaltar los procesos de la vida cotidiana en otras épocas. Las artes escénicas no tenían la conexión que hoy tienen con espacios diseñados para su exhibición, sino que eran parte de la vida significativa de una comunidad organizada. Dentro de estas expresiones la música y el canto eran parte de los ritos y las ceremonias que consumaban la significación de la vida del grupo.

En esta línea que valora lo artístico como desarrollo social se encuadra el concepto de desarrollo cultural comunitario. A través de la cultura (entendida como medio, metodología o contenido) se posibilita que las personas, los grupos y las comunidades actúen sobre sí mismos con el fin de mejorar su estar en el mundo y, en general, su calidad de vida. Se trata de conseguir la transformación social a través del arte y la creatividad utilizando la cultura como elemento de desarrollo.

\section{LA EDUCACIÓN MUSICAL EN EL SISTEMA EDUCATIVO}

Expuesto lo anterior, comprendiendo la importancia que tiene la música en nuestra vida y el papel que juega en el día a día de nuestros jóvenes, sumergirnos en el sistema educativo y hablar de educación musical exige que distingamos tres ámbitos de formación claramente diferenciados, a pesar de que a lo largo de la historia hayan podido llegar a confundirse y alguno de ellos haya estado menos definido: la formación musical profesional, la formación docente para el ámbito musical, y la música como parte de la formación general. Es decir, podemos hablar de educación "para" la música, pero además, podemos hablar de educación general "por" la música.

El marco legislativo actual incluye la educación musical como parte de la formación general de los individuos y, por lo tanto, la reconoce como ámbito de intervención educativa propio y singular. La normativa distingue entre educación musical con valor de educación general y educación musical con sentido profesional, en la misma medida en que diferencia la educación artística y las enseñanzas artísticas.

A partir de la Ley Orgánica 2/2006, de 3 de mayo, de Educación (LOE) (BOE del 4 de mayo) las enseñanzas de música, danza, arte dramático, conservación y restauración de bienes culturales, arte plástico y diseño pasan a denominarse enseñanzas artísticas, integrándose dentro del sistema educativo. Se plantea por tanto una nueva realidad: ni se trata de preparar a todos como si fueran a ser instrumentistas expertos, ni de que todos sean vocacionalmente músicos. Se trata de que la música sea para la educación una dimensión de intervención general y como tal es susceptible de ser tratada, como un problema pedagógico general que permite desarrollar competencias que implican destrezas, hábitos, actitudes y conocimientos de manera integral y no diferencialmente, como si sólo fueran competencias profesionales. En la educación musical como ámbito de educación general, hablamos de un área de intervención orientada al desarrollo y

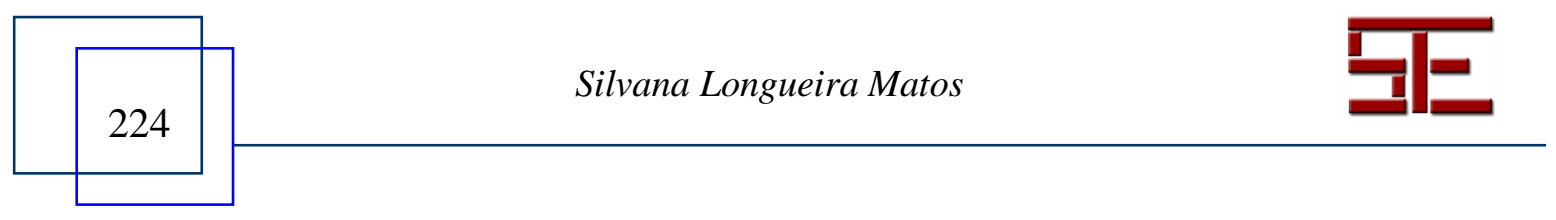




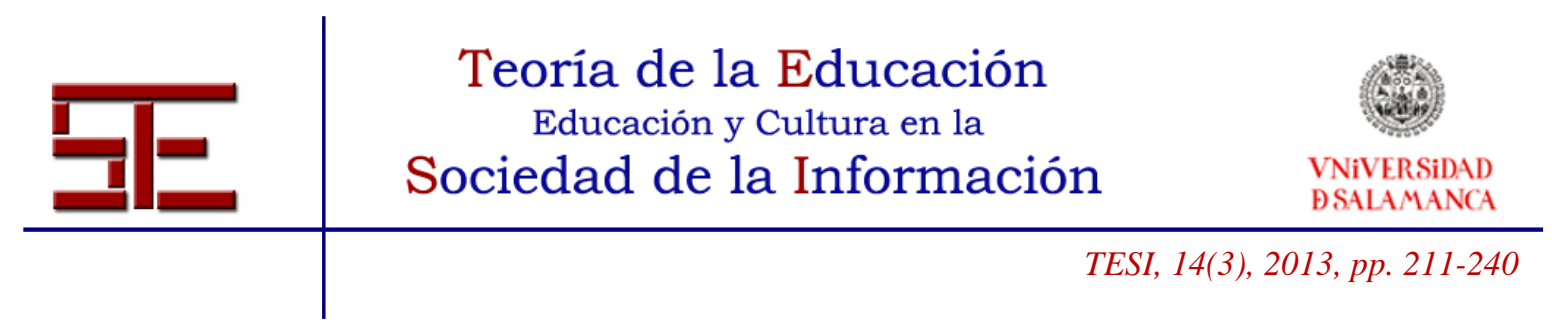

construcción de la persona desde la experiencia artística musical, sea o no el alumno, músico vocacional, o un futuro profesional de la música (Touriñán y Longueira, 2009 y 2010a).

Actualmente la oferta de enseñanza musical fuera de los niveles educativos generales, formación musical profesional o vocacional, cuenta con dos vías: la reglada y la no reglada. La primera se desarrolla en los conservatorios de música y en la universidad, y está encaminada a la obtención de títulos con validez académica y profesional. La segunda modalidad se circunscribe al ámbito de las escuelas de música que se regulan por normas de las diferentes Administraciones educativas. La formación musical profesional se imparte en los conservatorios de música y en el grado universitario de Historia y Ciencias de la Música. Además, algunas universidades han aprobado títulos propios relacionados con la gestión cultural y artística, y con la musicoterapia. La Formación Profesional viene impartiendo titulaciones relacionadas con imagen y sonido.

\subsection{Educación "por" y "para" la música}

Tal y como se ha recogido en trabajos anteriores (Touriñán y Longueira, 2009; Longueira, 2012) y lo desarrollado en el apartado anterior, la Ley Orgánica 2/2006, de 3 de mayo, de Educación (LOE) (BOE del 4 de mayo) establece el concepto de enseñanzas artísticas, que quedan integradas en el sistema general de formación. Se plantea, por tanto, un nuevo matiz legal en nuestro sistema educativo, porque, además de las enseñanzas artísticas (en nuestro caso, educación "para" la música: vía vocacional y profesional), se integra la educación musical como parte del currículum general de primaria y secundaria (en nuestro caso, educación "por" la música, pues se admite implícitamente que ni se trata de preparar a todos los alumnos de la educación común y obligatoria como si fuesen a ejercer profesionalmente como instrumentistas expertos, ni de presuponer erróneamente que todos los alumnos de la educación general eligen vocacionalmente la música). En la educación musical como concepto pedagógico de formación general, hablamos de un área de intervención orientada al desarrollo y construcción de la persona educando basada en competencias adquiridas desde la cultura musical que permiten aunar inteligencia, voluntad y afectividad en el desarrollo de toma de decisiones personales que tienen implicación en cada proyecto de vida, sea o no el alumno vocacionalmente músico o quiera ser en el futuro, un profesional de la música (Touriñán y Longueira, 2009).

En los últimos años la demanda social hacia una educación musical de calidad se ha multiplicado, alcanzado cotas muy elevadas, lo que ha generado un crecimiento importante de escuelas y conservatorios de música. Actualmente los centros de educación musical no reglada (escuelas de música privadas, municipales o con carácter

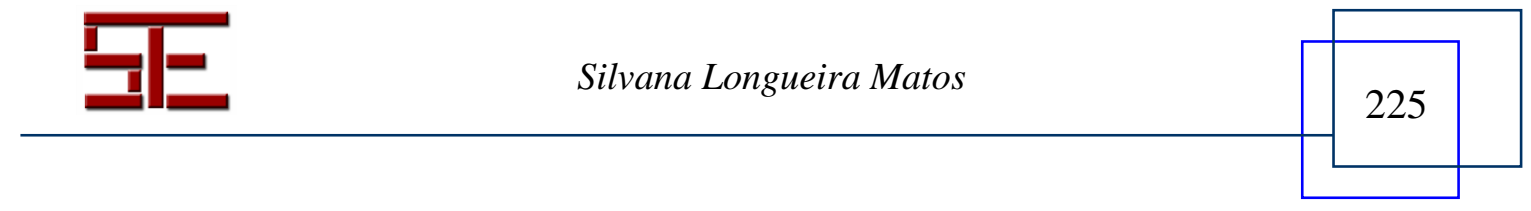




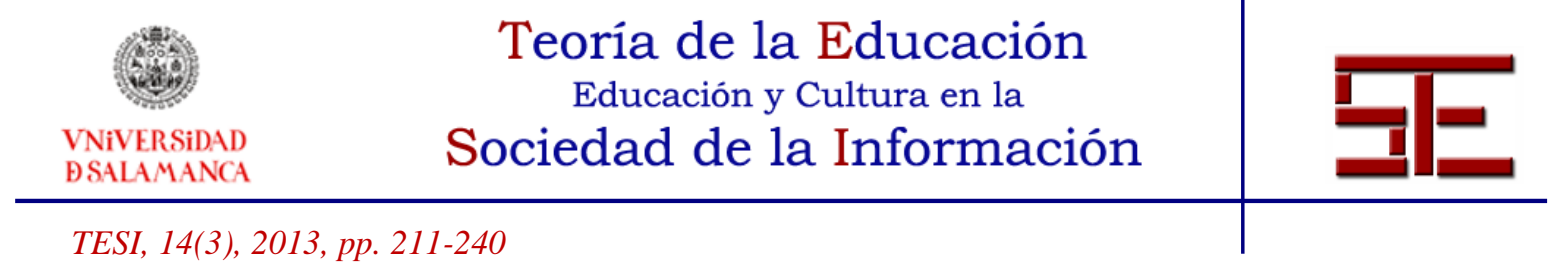

de asociación cultural) y los centros de educación musical reglada (públicos o autorizados) han aumentado su presencia, multiplicando las plazas ofertadas y las posibilidades de acceso de la población a una educación musical fuera del sistema educativo obligatorio, entendida como formación alternativa y paralela al mismo. En los cálculos de inversión publicados por el Ministerio de Educación, Cultura y Deporte (www.educación.gob.es) que se refieren al ejercicio 2010, se estima que un 2,2\% del gasto público en educación se destina a enseñanzas de régimen especial (Ministerio de Educación, Cultura y Deporte, 2012). Según los datos y cifras publicados por el mismo organismo, en el curso 2011-2012 alrededor de 310.260 alumnos han cursado educación musical fuera del sistema general, de los cuales 45.247 estaban matriculados en enseñanzas elementales, 40.882 en enseñanzas profesionales y 216.709 en enseñanza no reglada (Ministerio de Educación, 2013). Incluso en esa oferta, inicialmente ideada como educación "para" la música, podemos comprobar que cada vez más, hay alumnado que confía en las posibilidades de la educación musical como área de formación y educación portadora de numerosas capacidades para el desarrollo integral; es decir, incluso los alumnos vocacionales esperan recibir educación "por" la música.

En definitiva, es ya incuestionable, desde el punto de vista legal, que la educación musical como formación general (la educación "por" la música) es un ámbito de intervención pedagógica que debe ser abordado desde la formación general del individuo y no sólo como ámbito de especialización o profesionalización. Esta diferenciación no es menor en el tema que nos ocupa, la música es un medio generador de conocimientos y capacidades generales y básicas; esta mirada está enormemente mediada en nuestro entorno por la tradición y la dimensión profesionalizadora, en gran parte heredada del papel que en la historia de la educación más reciente la música ha desempeñado.

\subsection{La música en los planes de estudios de la formación general}

Actualmente la educación musical o Música, como se la denomina en tanto que materia de enseñanza, tiene asignados unos tiempos y niveles dentro de las enseñanzas generales del sistema educativo que responde a la formación que queremos para el hombre actual, como consecuencia de decisiones de política educativa. Así se considera que la formación musical tiene algo que aportar a estos fines y asume representación en Educación Infantil, Primaria y Secundaria. En el primero de los niveles, regulado por el Real Decreto 1630/2006, de 29 de diciembre, por el que se establecen las enseñanzas mínimas del segundo ciclo de Educación Infantil (BOE del 4 de enero), la música se incluye como el bloque 3, dentro de Lenguaje Artístico, como parte del área de Lenguaje: Comunicación y Representación. Tal clasificación reclama la atención de este trabajo, ya que se está reconociendo la música como lenguaje que nos permite comunicarnos con otros y establecer códigos de representación.

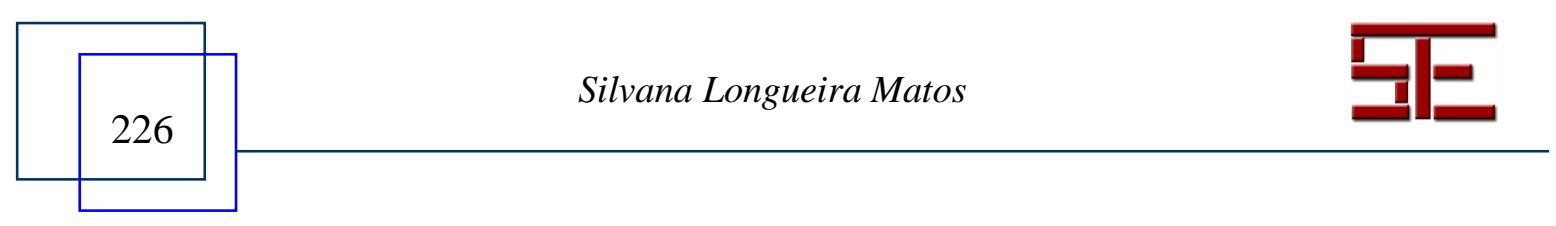




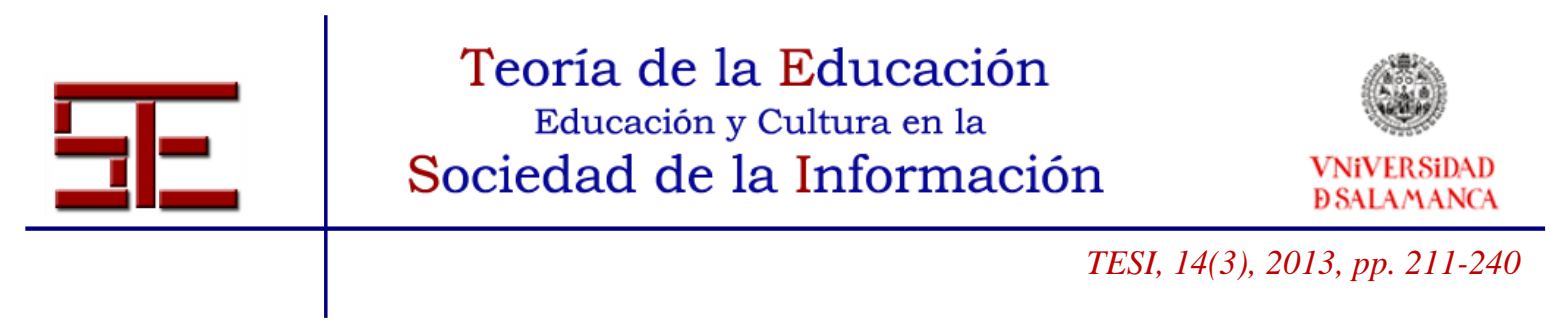

En la Educación Primaria, el Real Decreto 1513/2006, de 7 de diciembre, por el que se establecen las enseñanzas mínimas para este nivel (BOE del 8 de diciembre), se contemplan 105 horas de educación artística en cada ciclo, en las que está incluida la educación musical. El Real Decreto 1631/2006, de 29 de diciembre (BOE del 5 de enero) que establece las enseñanzas mínimas para el nivel de Secundaria Obligatoria, concede a la asignatura de Música 105 horas mínimas para los tres primeros cursos con carácter obligatorio y 70 horas en el cuarto curso como oferta optativa. Los objetivos se dividen en cuatro bloques denominados Escucha, Interpretación, Creación y Contextos musicales.

\subsection{La competencia cultural y artística}

La tendencia institucional e internacional que reconoce el arte como parte idiosincrásica de la cultura y los estudios de corte antropológico y etnomusicológico sobre las implicaciones del arte, de la música, en lo social, se han reflejado de forma vaga en los currículos educativos. Nuestro sistema educativo, a través de las normas que desarrollan los currículos de los diferentes niveles educativos generales vertebra la enseñanza en ocho competencias básicas entre las que se encuentra la competencia cultural y artística. De este modo se reconoce que es necesaria educación y formación para dos ámbitos que tienen una presente y una influencia constante, más en un entorno global donde las tecnologías de la información y la comunicación son inimaginables sin la influencia de la estética y el arte (Hennion, 2010).

El Real Decreto 1513/2006, de 7 de diciembre, por el que se establecen las enseñanzas mínimas de la Educación Primaria y el Real Decreto 1631/2006, de 29 de diciembre, por el que se establecen las enseñanzas mínimas correspondientes a la Educación Secundaria Obligatoria, recogen que la competencia cultural y artística

“(...) supone conocer, comprender, apreciar y valorar críticamente diferentes manifestaciones culturales y artísticas, utilizarlas como fuente de enriquecimiento y disfrute y considerarlas como parte del patrimonio de los pueblos. Apreciar el hecho cultural en general, y el hecho artístico en particular, lleva implícito disponer de aquellas habilidades y actitudes que permiten acceder a sus distintas manifestaciones, así como habilidades de pensamiento, perceptivas y comunicativas, sensibilidad y sentido estético para poder comprenderlas, valorarlas, emocionarse y disfrutarlas".

Es una competencia que facilita tanto expresarse y comunicarse como percibir, comprender y enriquecerse con diferentes realidades y producciones del mundo del arte y de la cultura relacionándose con:

1.la habilidad de poner en juego pensamiento divergente y convergente, puesto que comporta reelaborar ideas y sentimientos propios y ajenos;

2.encontrar fuentes, formas y cauces de comprensión y expresión;

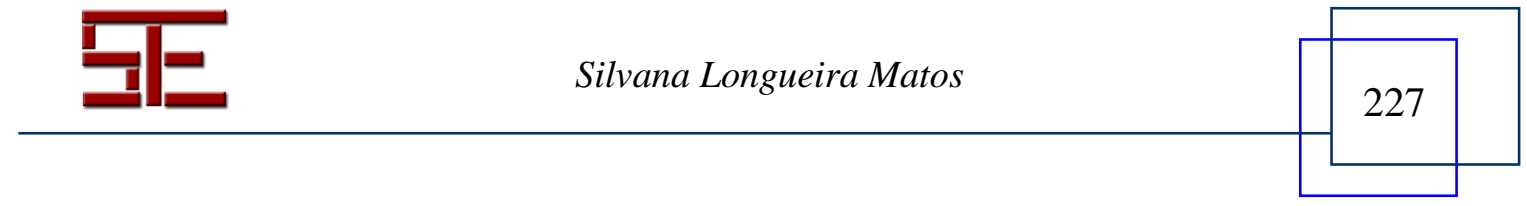




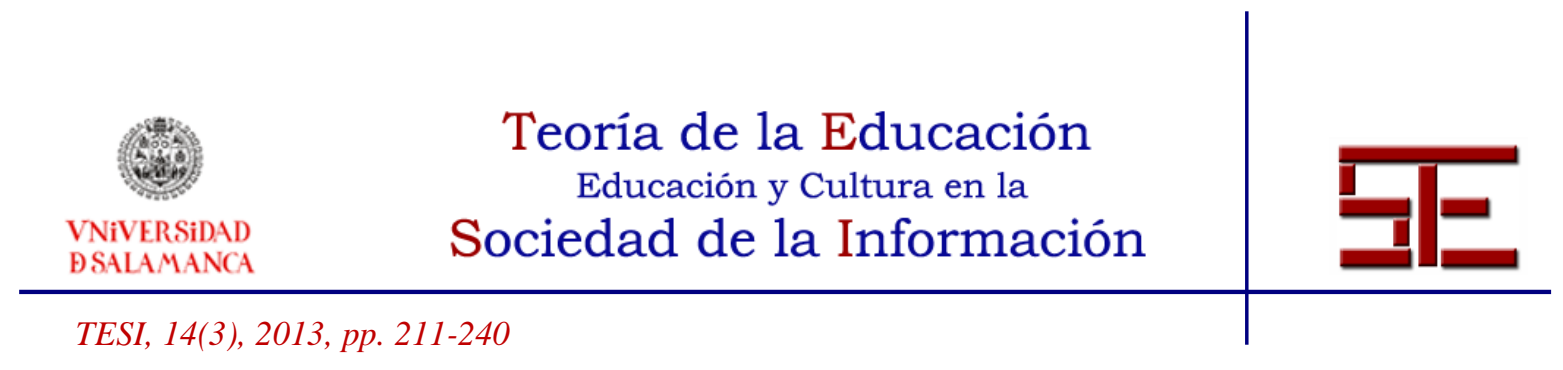

3.planificar, evaluar y ajustar los procesos necesarios para alcanzar unos resultados, ya sea en el ámbito personal o académico.

Requiere poner en funcionamiento:

- la iniciativa, la imaginación y la creatividad para expresarse mediante códigos artísticos;

- habilidades de cooperación en la medida en que las actividades culturales y artísticas suponen en muchas ocasiones un trabajo colectivo;

- conciencia de la importancia de apoyar y apreciar las iniciativas y contribuciones ajenas;

- valorar la libertad de expresión y la trascendencia del diálogo intercultural.

Por último, se señala en la citada normativa que el conjunto de destrezas que configuran esta competencia se refiere tanto a la habilidad para apreciar y disfrutar con el arte y otras manifestaciones culturales, como a aquellas relacionadas con el empleo de algunos recursos de la expresión artística para realizar creaciones propias; implica un conocimiento básico de las distintas manifestaciones culturales y artísticas, la aplicación de habilidades de pensamiento divergente y de trabajo colaborativo, una actitud abierta, respetuosa y crítica hacia la diversidad de expresiones artísticas y culturales, el deseo y voluntad de cultivar la propia capacidad estética y creadora, y un interés por participar en la vida cultural y por contribuir a la conservación del patrimonio cultural y artístico, tanto de la propia comunidad, como de otras comunidades.

\subsection{La profesionalización de la música: los conservatorios}

Los conservatorios de música se dividen en elementales, profesionales y superiores. Cada uno de estos niveles, de cuatro, seis y cuatro cursos respectivamente da lugar al diploma o título correspondiente. La clasificación de estos grados y las materias que componen los planes de estudios para cada uno de ellos vienen configuradas de forma muy similar desde 1830 situando la formación instrumental como eje vertebrador del currículo.

Actualmente los conservatorios superiores están sumidos en la búsqueda de la solución más adecuada para la adaptación al Espacio Europeo de Educación Superior (EEES). Tras la anulación de la normativa por la cual se habían diseñado los grados de las especialidades artísticas superiores, muchos ven como una posible alternativa su ingreso en la Universidad, dando una salida a la actual duplicación de titulaciones y evitando buscar fórmulas alternativas de adaptación de los títulos. Sin embargo, la inversión económica y las dificultades administrativas tales como la asimilación de los planes de estudios y la contratación del profesorado pueden ser retos difíciles de resolver.

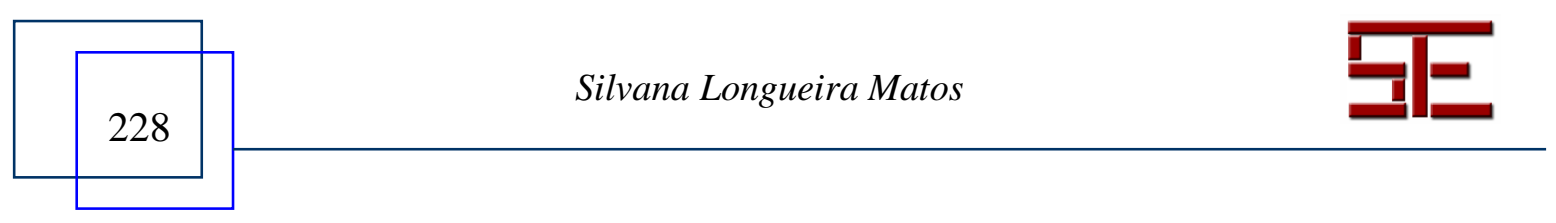




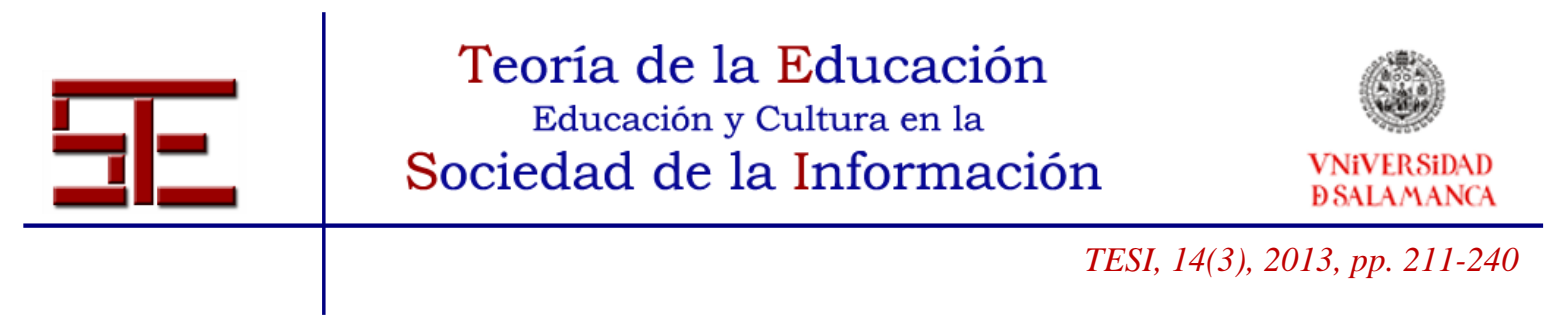

\subsection{Más que una aproximación vocacional: las escuelas de música}

La LOE reconoce la posibilidad de desarrollar estudios musicales sin validez académica o profesional en escuelas específicas reguladas por las Administraciones educativas. Hoy las escuelas de música públicas registradas en las diferentes Administraciones educativas son un espacio de formación organizado y sistematizado donde poder desarrollar el interés vocacional por un instrumento sin pretender por ello obtener un título oficial. Son un nexo entre formación general y formación profesional, con un currículo y metodología flexibles.

Así mismo configuran una segunda oportunidad dentro de la formación a lo largo de toda la vida.

La supervivencia de los conservatorios de música y las escuelas de música municipales queda pendiente de resolver por la reforma de competencias de la administración local.

\section{LA EDUCACIÓN MUSICAL COMO ÁMBITO GENERAL DE EDUCACIÓN}

Para comprender el lugar que ocupa la música en la educación general y las aportaciones que desde esta área de formación se pueden derivar hacia el desarrollo en una sociedad del conocimiento, es necesario abordar los conceptos de dimensiones, ámbitos y finalidades. Todo ello justifica la música como parcela de la educación susceptible de intervención pedagógica orientada al desarrollo de habilidades, competencias y valores útiles en un mundo global.

\subsection{Dimensiones, ámbitos y finalidades en la educación}

Desde el punto de vista de la intervención pedagógica, debemos tener en cuenta los siguientes componentes: agentes, procesos, medios, producto, áreas de experiencia, formas de expresión y dimensiones o niveles de intervención (Touriñán, 2010; Longueira, 2012).

En el lenguaje pedagógico debemos tener claro los siguientes aspectos:

-Las dimensiones generales de intervención se identifican con inteligencia, voluntad y afectividad. En la relación educativa, cada vez que se interacciona, se actúa sobre y con cada una de estas tres dimensiones, aunque no siempre con el mismo peso o en la proporción conveniente.

- Las áreas de experiencia tratan de construir experiencia en el educando por medio de la educación, en cada parcela o ámbito de intervención: educación artística, socio-histórica, filosófico-trascendental, físico-natural, científico-tecnológica, geográfico-ambiental, etc.

-Las formas de expresión se refieren a educación rítmica y gestual, linguiística, matemática, estética, audiovisual-virtual, etc. En cada área de experiencia, la educación pretende que el

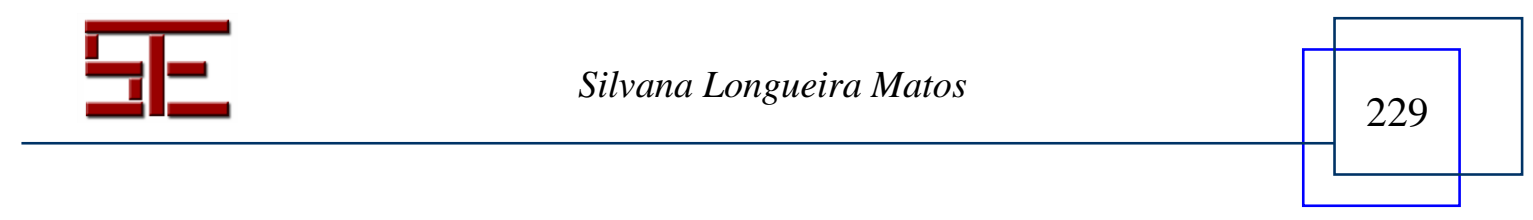




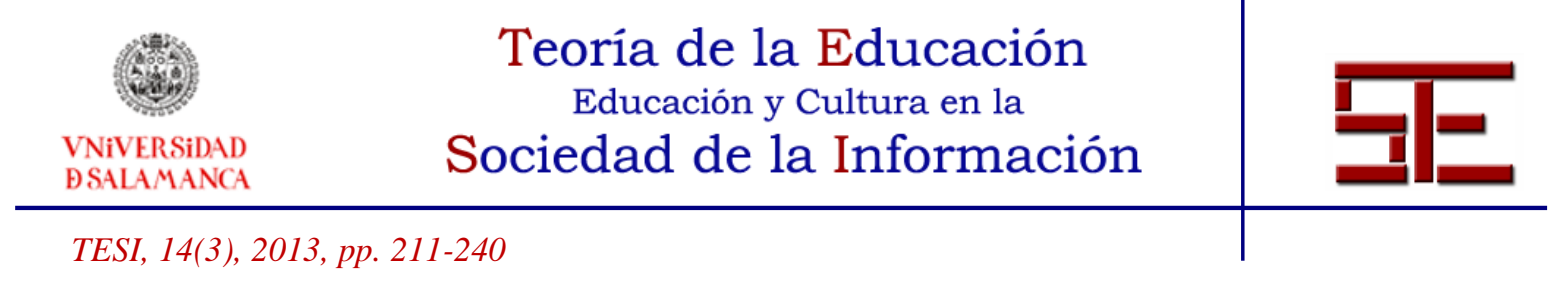

educando adquiera la mejor manera de expresar su logro o competencia y para ello hay que dominar las formas de expresión más ajustadas a cada área de experiencia.

Las áreas de experiencia y las formas de expresión se integran en los ámbitos de educación y cada área de experiencia puede requerir diversas formas de expresión para dominar las competencias correspondientes. Las áreas de experiencia y las formas de expresión son susceptibles de intervención pedagógica y para el desarrollo de la competencia en cada caso se requiere la intervención, atendiendo a las tres dimensiones generales. Por esa presencia general de las tres dimensiones en cada actuación educativa, que marcan la naturaleza de la educación, se habla del carácter de la educación como integral, personal, axiológico y patrimonial. Pero, además, dado que en la relación educativa actuamos siempre con una determinada perspectiva de orientación o finalidad cualificadora en un momento socio-histórico específico, es decir, con un determinado sentido finalista de la educación, podemos hablar también y con propiedad del sentido de la educación, que, en nuestros días, es intercultural, permanente, glocal (global y local al mismo tiempo), general y profesional-vocacional. Un sentido que se sustenta en raíces pedagógicas y se aplica desde diversos y variados estratos de pensamiento, sin que se confunda ni se identifique con ellos necesariamente, porque el sentido de la educación es específico, distinto y propio de ese ámbito de realidad. Carácter y sentido son los dos elementos que determinan el significado de la educación (Touriñán, 2010; Longueira, 2012). En la figura 2 se representa de forma sintética la relación de estos elementos.

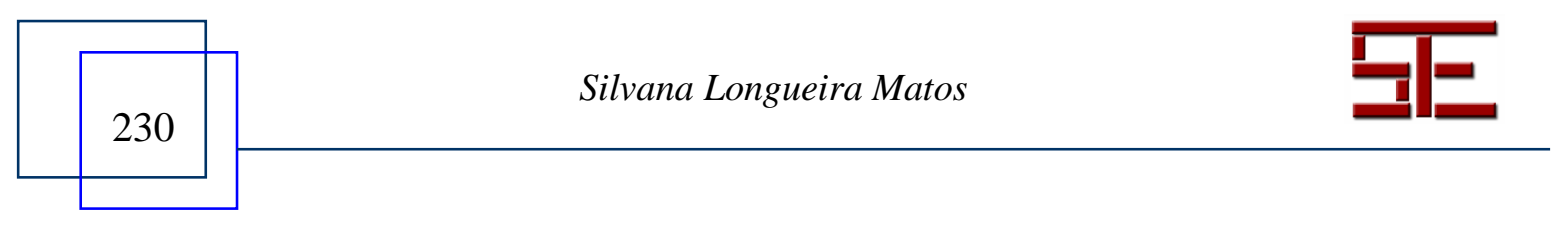




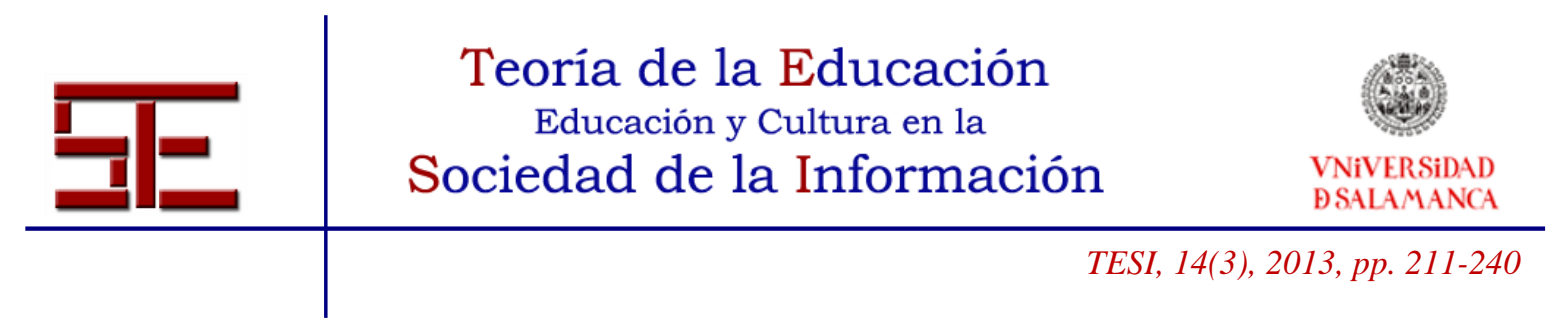

Figura 2. Educación artística como parcela o ámbito general de educación.

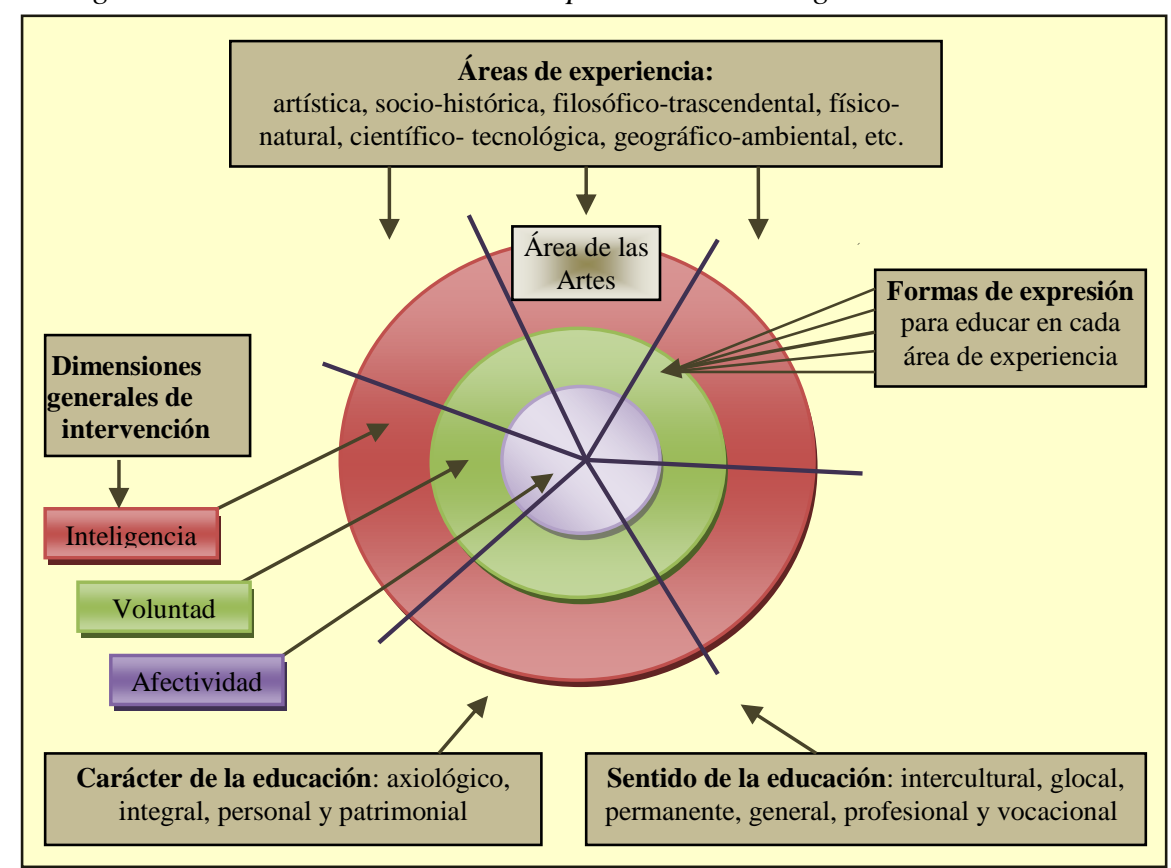

Fuente: Touriñán, 2010, 56.

La educación musical es un valor elegido como finalidad educativa. Conforma una parcela de la educación sujeta a finalidades extrínsecas y a finalidades intrínsecas. Como finalidad extrínseca (meta educativa) es un área cultural condicionada social e históricamente respecto de lo que es educación artística a la altura de los tiempos en cada momento. Como finalidad intrínseca (meta pedagógica) es una parcela de la educación susceptible de intervención pedagógica y que contribuye a la realización de la finalidad de la educación, proporcionando destrezas, hábitos, actitudes y conocimientos de valor educativo reconocido para construirse a uno mismo, para educarse y desarrollarse profesionalmente (Touriñán, 2010).

\subsection{La educación "por" la música. La música como instrumento de educación y de educación artística}

Argumentado que la educación musical, además de ámbito de formación profesional y vocacional, puede formar parte de la educación general, debemos afianzar la tesis de que la música es instrumento de educación y de educación artística, ya que a través de la

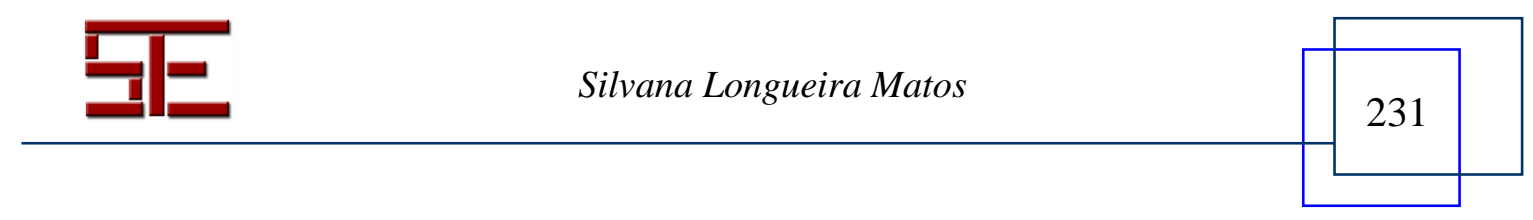




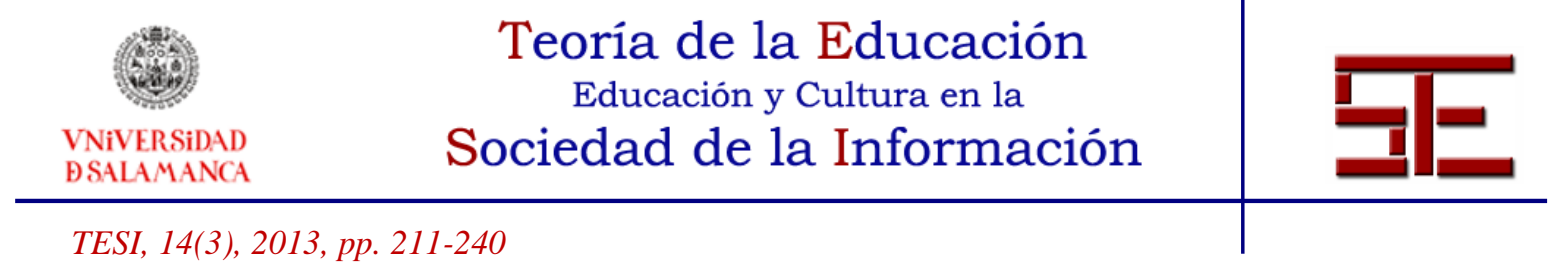

música podemos desarrollar competencias generales en el educando, muchas de ellas relacionadas con la sociedad del conocimiento (Touriñán y Longueira, 2010).

La educación musical es una parcela de la educación y no sólo se puede generar sobre ella conocimiento de la educación, sino que debido a ese conocimiento puede ser entendida como ámbito de educación general y como ámbito general de educación. Además, como ya hemos visto, es un ámbito que puede ser aprendido y enseñado en forma de carrera organizada con disciplinas científicas, académicas y asignaturas de planes de estudios.

La educación musical es ámbito de educación general, porque forma parte del currículo de la educación general, se considera necesario para el desarrollo integral del individuo y se contempla en esos términos en los planes de estudios de educación primaria y secundaria obligatoria (apartado 4.2.) como ámbito de intervención pedagógica que debe ser abordado desde la formación general de cada educando y no sólo como ámbito de especialización o profesionalización.

Respecto de estas matizaciones conceptuales, conviene decir en este apartado que, a pesar de que conocemos el peso determinante que ha tenido la música en algunas culturas, no en todas las épocas se ha valorado de igual manera. El desarrollo cultural de una sociedad y la valoración que hace de los diferentes ámbitos de saber, condiciona la estructura curricular de la educación general. Nuestra sociedad, en las últimas décadas, ha aprendido a valorar el hecho musical como parte de la oferta cultural (Hennion, 2002; Marco, 2002; Small, 2006; Merrian, 2001), aunque en muchas ocasiones se ha relegado a un modo de oferta cultural dirigido a las élites y separando el hecho artístico de la forma de expresión y de la experiencia, lo que ha generado modelos contemplativos de relación con la música. De manera progresiva, en las dos últimas décadas, se ha observado el nacimiento y consolidación de formaciones instrumentales en las principales ciudades del territorio nacional, configurando auditorios, ciclos y programas de conciertos estables que forman parte ya de la vida y el reclamo cultural de nuestro entorno, así como una opción más extendida dentro del espacio de ocio y tiempo libre.

Sin embargo, este interés surge paralelo a una demanda social de una educación musical generalizada como ya hemos comentado, lo que contribuye de manera significativa a la evolución de la educación musical en los años noventa, tanto dentro de la escuela como en los centros especializados. Ahora bien, tan lícito como ese desarrollo profesional, es encontrar la respuesta adecuada a la pregunta acerca del modelo de ser humano que queremos desarrollar en la sociedad actual, qué saberes debe dominar la persona social y culturalmente valorada, hasta el punto de defender la música como parte de los contenidos de las metas culturales y sociales en nuestra educación actual, y como valor desde el conocimiento de la educación (finalidad intrínseca y extrínseca). La respuesta afirmativa a esa cuestión nos obliga a pensar en qué destrezas, hábitos y actitudes

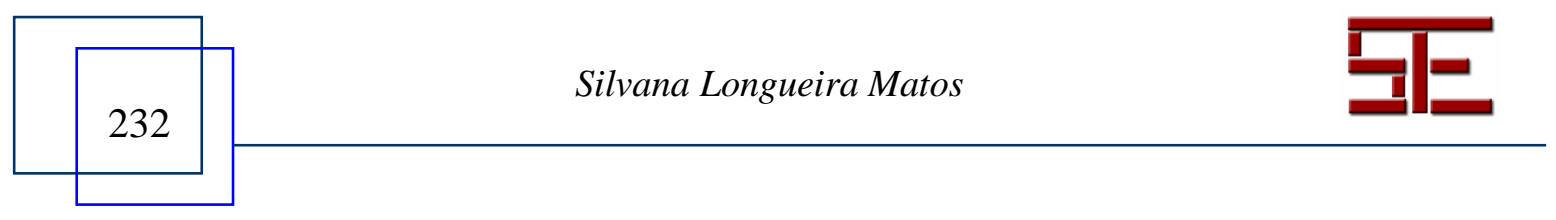




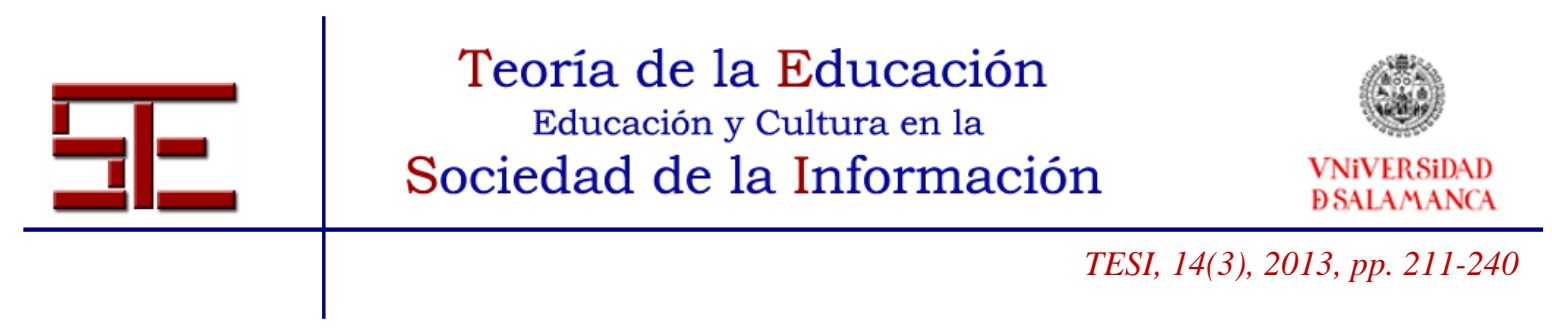

podemos desarrollar a partir de la música, o lo que es lo mismo, a qué ámbitos fundamentales del desarrollo integral puede contribuir la música dentro de la educación general. Esta pregunta da sentido a la expresión "educación por la música.

Se trata de no perder la perspectiva general y entender que, a través del ámbito musical se adquiere experiencia axiológica, que permite relacionarnos con los demás, decidir el proyecto de vida personal y tomar decisiones. Para ello no se necesita saber "mucha" música, como si de una formación de nivel profesional se tratara, sino que, como ámbito de educación, la música sirve a cada educando para usar y construir experiencia valiosa para su propia vida y formación integral, desde la experiencia artística musical.

Si se pierde esta perspectiva general, los ámbitos de educación se confunden con sus contenidos cognoscitivos y la música se identifica sólo con destrezas psicomotrices y con historia de la música. Esa mentalidad, que limita la educación musical a la orientación profesional y vive la educación musical en términos de pericia instrumental y nivel de información sobre la evolución musical en la historia, ha contribuido a configurar una arquitectura disciplinar de educación musical basada en bloques curriculares independientes que no contempla la intervención pedagógica en el ámbito de la educación artístico-musical como ámbito general de educación y como ámbito de educación general.

Cuando se habla de la música como ámbito de educación con sentido general, queremos decir que la música sirve a cada educando para usar y construir experiencia valiosa para su propia vida y formación, desde la experiencia artística musical, manteniendo el carácter axiológico, integral, personal y patrimonial propio de la educación (Touriñán, 2008).

La educación musical debe tener carácter integral, atendiendo la formación desde inteligencia, voluntad y afectividad con el objetivo de afrontar con libertad y posibilidades de éxito las diferentes situaciones que se nos plantean en los distintos ámbitos de la vida (personal, familiar, social, profesional, etc.). Tradicionalmente inteligencia y voluntad han recibido toda la atención en la educación, sin embargo, tal y como plantean Alonso, Pereira y Soto (2003), los valores y las actitudes son esenciales para el ser humano porque constituyen la estructura más profunda de la personalidad a la vez que orientan y motivan su conducta. Consecuentemente, la función axiológica y actitudinal de la educación, y no sólo la instructiva, es ineludible.

El modelo de escuela que prima la acumulación de conocimiento y disciplina jerarquizada está obsoleto frente a las demandas del contexto contemporáneo. La sociedad del conocimiento es tal porque ha conseguido traducir la información en conocimiento. El reto actual es convertir ese conocimiento en saber.

Cuando hablamos del carácter personal de la educación, nos referimos a la capacidad de crear modelos propios, originales, singulares y autónomos, dentro del espacio

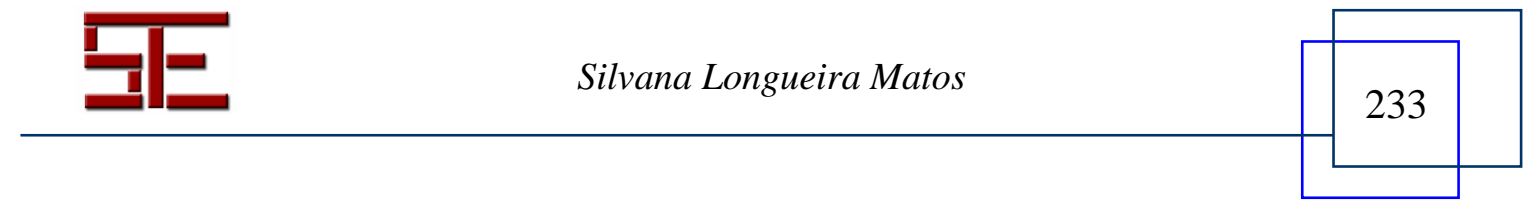




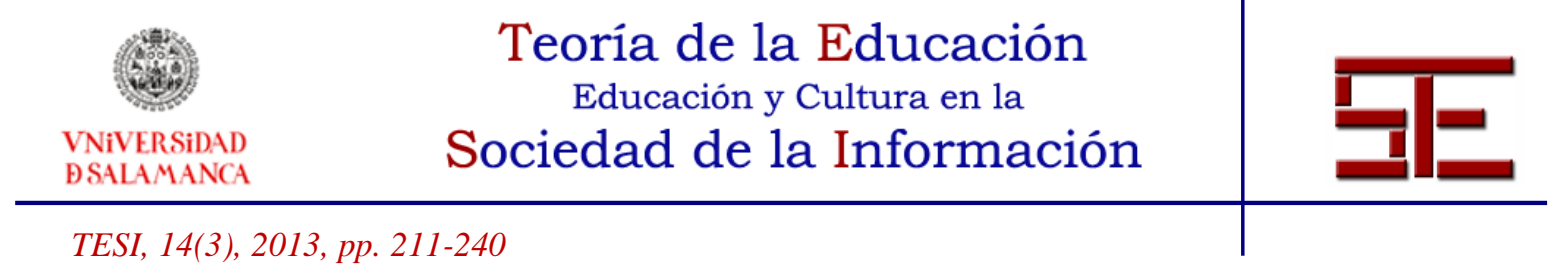

cultural, apartándose de la repetición de modelos preestablecidos. En este sentido la educación musical aporta un lenguaje amplio, alternativo, creativo, cuasi universal y con gran conexión con el ámbito afectivo, tan poco explorado en la educación. Además, nos permite reorientar los procesos educativos, insertando y aproximándonos a la diversidad de la creatividad cultural, así como el planteamiento de la música como manifestación intercultural. La música nos acerca a otros mundos desde un ámbito compartido. Nos ayuda a aproximarnos a la diversidad y la diferencia, así como a generar patrones de respuesta, desde el objetivo común y la comunicación.

Cuando hablamos del carácter patrimonial de la educación se hace hincapié en el modo en que cada uno se identifica con su formación y queda identificado por ella. Debido al carácter patrimonial de la educación, lo aprendido pasa a formar parte de la experiencia personal para construir con ella el propio proyecto de vida y de formación. En este sentido Ken Robinson expone que "una de las cosas que esperamos de la educación es que nos ayude a convertirnos en la mejor versión de nosotros mismos" (Smart Planet, 2011). Afirmar el carácter patrimonial de la educación quiere decir que somos, cada uno de nosotros mismos, un patrimonio; que aprendemos a elegir, a decidir y a marcarnos finalidades, para poder determinar nuestro proyecto de vida, dando respuesta a nuestras necesidades en cada circunstancia, construyéndonos a nosotros mismos como nuestro patrimonio más propio. La música posibilita en la formación general espacios y experiencias que obligan a elegir y a decidir valores respecto a la diversidad, la diferencia y fomenta la convivencia, predeterminando actitudes que se imprimen en nuestro patrimonio personal y nos ayudarán en la toma de decisiones de un mundo cada vez más complejo.

\section{CONCLUSIONES}

En el ámbito de la educación musical lo que urge no es un problema de más medios, ni de más recursos. Es un reto de mentalidad, cómo construimos la mirada pedagógica. Es necesario deshacerse de la influencia que el ámbito profesionalizador ha tenido sobre la educación musical en la educación general. El desarrollo administrativo de nuestro sistema educativo ha primado los estudios musicales orientados a la especialización con carácter profesional, desarrollados de forma paralela al sistema. Cuando a partir de 1990 con el desarrollo normativo de la LOGSE la educación musical se generaliza en las aulas de educación obligatoria, esta mentalidad sigue vigente. Todavía hoy se considera que las capacidades artísticas son de carácter innato, se tienen o no se tienen, pero no se defiende que todos podemos desarrollarlas, al menos desde el punto de vista competencial básico. Y es en este punto donde los trabajos científicos sobre el ámbito pedagógico musical deben dar un giro. Después de que la producción de las investigaciones se centrase en cómo se enseña mejor la música, debemos plantearnos cómo educar con la música. Saber música, enseñar música y educar con la música no se

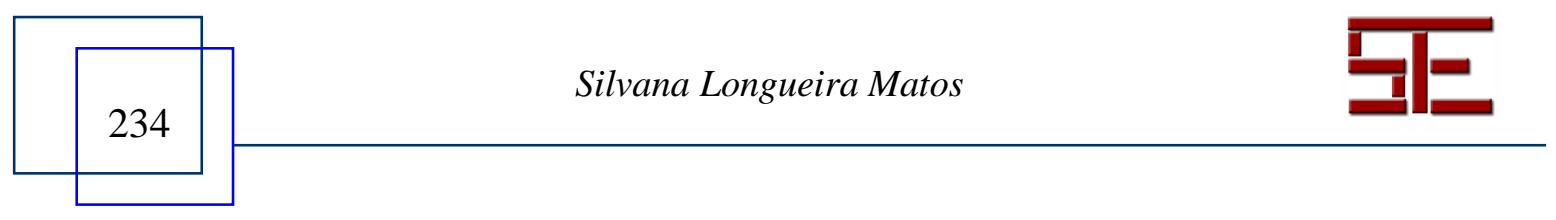




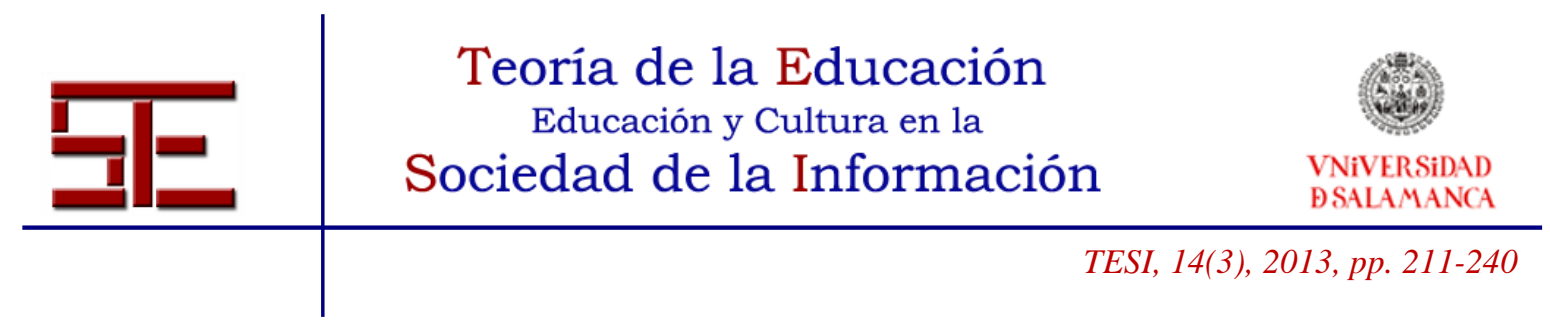

identifican. Por qué la música debe formar parte de los planes de estudios, qué nos puede ayudar a conseguir dentro de la educación general para todos los alumnos y por qué sigue siendo útil (más útil si cabe) ante los cambios y los retos sociales, de formación y comunicación a los que nos enfrentamos.

La concepción anacrónica que hemos arrastrado durante décadas (la influencia del desarrollo administrativo se remonta a 1830 con la creación del primer centro de enseñanza profesional en nuestro país y en pleno desarrollo del sistema escolar) ha abierto una brecha difícil de salvar por el alumnado entre la enseñanza secundaria y las enseñanzas superiores de música y ha perpetuado un sistema dual que ha ido difuminando la distancia entre enseñanzas artísticas y educación artística. Esto ha afectado al currículo de las artes en la educación general, a la formación del profesorado, a la valoración de la música por parte de la sociedad, al desarrollo de los centros orientados a la profesionalización y a la evolución de las enseñanzas artísticas superiores.

La demanda social de una educación de calidad no cesa. Conservatorios y escuelas de música ofertan cada año más plazas ante la concurrencia de las familias, que acuden a estos centros buscando lo que no encuentran en la escuela y generando en un gran número de casos un sentimiento de insatisfacción y frustración a medio plazo al encontrar unas exigencias demasiado altas, inspiradas en la concepción profesionalizadora, frente a la relación fluida y de interdependencia que los más jóvenes demuestran diariamente con el ámbito musical. Nuestros jóvenes y nuestro entorno es cada vez más dependiente de la música. La publicidad, los medios de comunicación y nuestro entorno comercial se sirven de la música como reclamo. Es más, como otros tantos ámbitos de consumo, el musical ha conseguido generarnos necesidades antes inexistentes. Somos grandes consumidores de productos musicales. La diversificación de formatos y el fácil acceso a estos productos nos posibilita cubrir nuestras necesidades de forma inmediata, en cualquier lugar y de forma económica. Y en gran medida esta necesidad de acceso rápido y efectivo se debe a que cada vez más reconocemos que la música modula y expresa con facilidad nuestros sentimientos. ¿Cómo es posible que un elemento tan presente en la vida de nuestros adolescentes suscite tanta indiferencia convertido en una materia del sistema educativo?

En gran medida nos sigue separando del ámbito artístico el concepto de cultura elitista. El prejuicio sobre la música clásica o sobre gran parte del arte contemporáneo se erige sobre un paradigma que pretende que el arte sea feudo de minorías. En este sentido numerosos autores, como hemos visto en el apartado 3, insisten en democratizar el arte e incluso ponen la mira en el proceso creativo frente al producto.

Debemos reorientar la mirada pedagógica. No se trata de saber mucha música, sino de que seamos capaces de educar con ella. La educación musical es una parcela de la educación y no sólo se puede generar sobre ella conocimiento de la educación, sino que

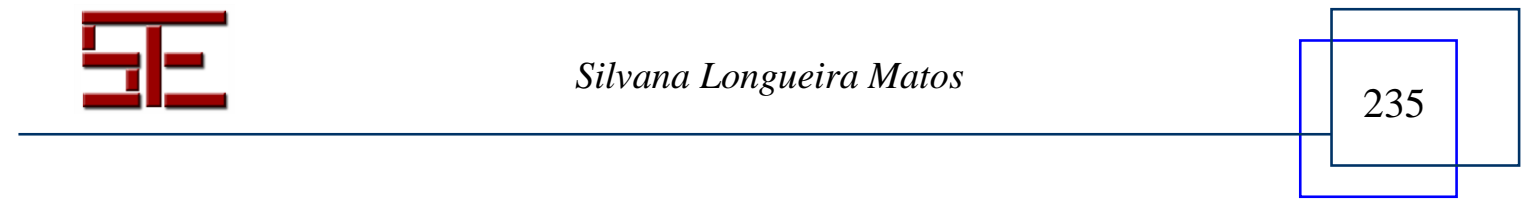




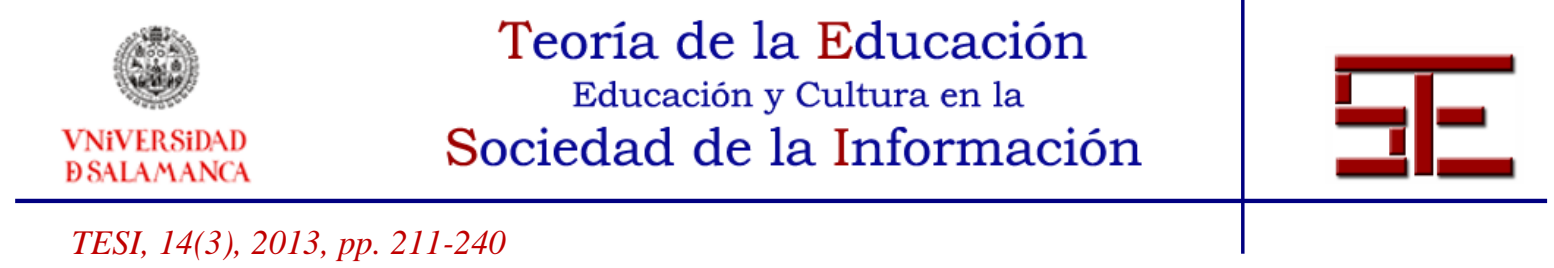

debido a ese conocimiento puede ser entendida como ámbito de educación general y como ámbito general de educación (además de un ámbito que puede ser aprendido y enseñado en forma de carrera organizada con disciplinas científicas, académicas y asignaturas de planes de estudios). Desde esta perspectiva, la educación musical no es sólo educación "para" la música, desarrollo vocacional y carrera profesional; también es educación "por" la música, ámbito de educación general -a todos los alumnos- y ámbito general de educación que permite focalizar la intervención pedagógica en el desarrollo de competencias generales de la educación, como parte del desarrollo integral del educando, igual que las matemáticas, la lengua, la geografía, o cualquier disciplina básica del currículum de la educación general.

Se trata de no perder la perspectiva general y entender que, a través del ámbito musical se adquiere experiencia axiológica, que permite decidir el proyecto de vida personal y tomar decisiones en el contexto que nos ha tocado vivir. Para ello no se necesita saber "mucha" música, como si de una formación de nivel profesional se tratara, sino que, como ámbito de educación, la música sirve a cada educando para usar y construir experiencia valiosa para su propia vida y formación integral, desde la experiencia artística musical.

En una sociedad donde el acceso a la información es inmediato, la capacidad de seleccionar, ordenar y valorar nos dará la posibilidad de convertirla en conocimiento. Esta es la meta de la sociedad actual, la sociedad del conocimiento. Sin embargo, el verdadero reto se presenta al pretender completar el proceso para traducir el conocimiento en saber. Las aceleradas transformaciones del mundo que nos rodea exigen nuevas competencias y nuevas capacidades que debemos ayudar a desarrollar desde la formación general. La música no sólo es ámbito de educación como tradicionalmente lo han sido otras materias, sino que presenta potencialidades excepcionales para el desarrollo de capacidades en la sociedad del conocimiento.

La inclusión de las artes y de la música en la actividad educativa tiene relación con el modelo de ser humano y el modelo de sociedad que queremos. La primacía de los valores vinculados al sentido conceptual de la música y al desarrollo científicotecnológico no permite la realización plena de las posibilidades de la educación de las personas que pasa necesariamente por el fortalecimiento de las artes como parte del desarrollo dimensional de cada uno. La educación "por" las artes fortalece el desarrollo de las áreas de experiencia y de las formas de expresión, a partir de la educación en valores éticos, estéticos y sociales.

\section{REFERENCIAS}

Alonso, $M^{\mathrm{a}}$ L., Pereira, $\mathrm{M}^{\mathrm{a}}$ C. y Soto, J. (2003). La educación en valores a través de la música. Marco teórico y estrategias de intervención. En $\mathrm{M}^{\mathrm{a}} \mathrm{C}$. Benso y $\mathrm{M}^{\mathrm{a}} \mathrm{C}$. Pereira (Coords.), $E l$

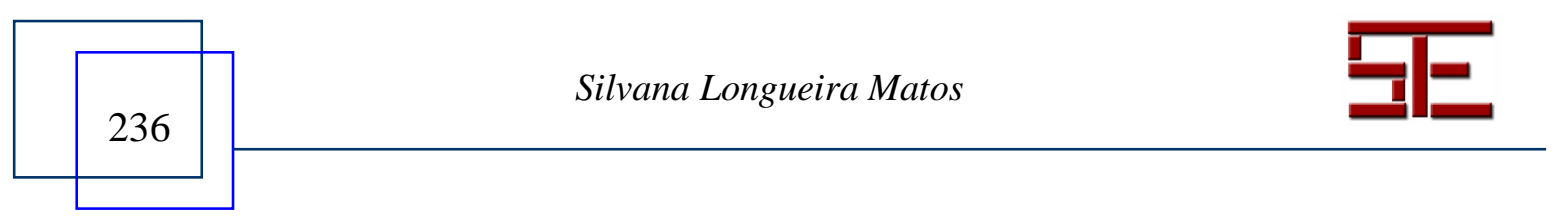




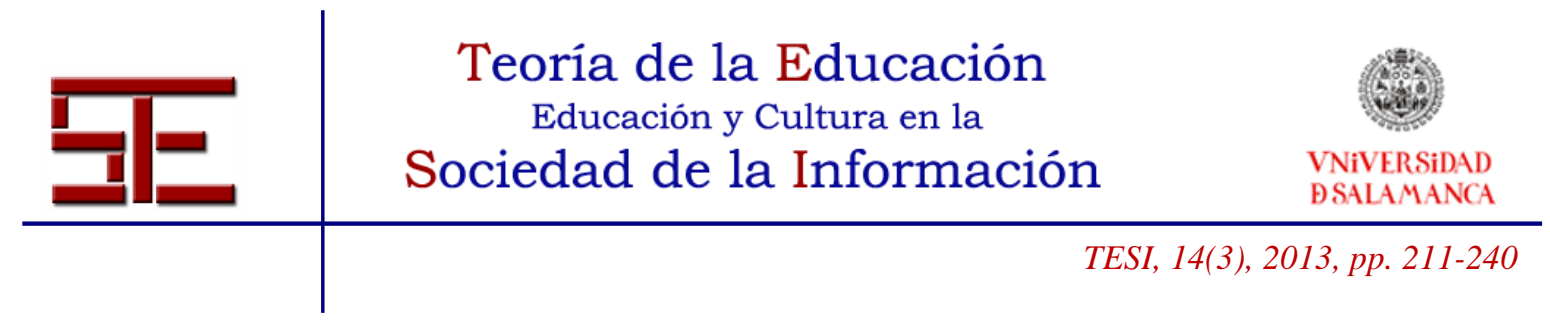

profesorado de enseñanza secundaria. Retos ante el nuevo milenio (pp. 135-202). Ourense: Auria.

Asamblea de las Regiones de Europa (1996). Declaración sobre el regionalismo en Europa. Basilea, 4 de diciembre. Extraído el 8 de junio, 2013, de http://www.aer.eu.

Ayuste, A., Gros, B. y Valdivieso, S. (2012). Sociedad del conocimiento. Perspectiva pedagógica. En L. García Aretio, Sociedad del conocimiento y educación (pp. 17-40). Madrid: UNED.

Blacking, J. (1991). Towards a reintegration of musicology. En A. Buckley et al. (eds.), Proceedings of the British-Swedish conference on musicology: Ethnomusicology (pp. 61-69). Gotenburgo: Göteborgs Universitet, Institute of Musicology.

Blacking, J. (2001). El análisis cultural de la música. En F. Cruces y al., Las culturas musicales. Lecturas de etnomusicología (pp. 181-202). Madrid: Trotta.

Campbell, P. (1998). The Musical Cultures of Children. Research Studies in Music Education, 11, 42-51.

Claramonte, (2008). A modo de prólogo: algunas ideas para leer con Dewey. En J. Dewey, El arte como experiencia. Barcelona: Paidós.

Consejo de la Unión Europea (2007). Resolución del Consejo de 16 de noviembre de 2007 sobre una Agenda Europea para la Cultura. Boletín Oficial de la Unión Europea C 287 de 29 de noviembre. Extraído el 8 de junio, 2013, de http://eur-lex.europa.eu/.

Cruces, F. (1998). Niveles de coherencia musical. La aportación de la música a la construcción de mundos. Antropología, (15-16), 33-58.

Cruces, F. y otros (2001). Las culturas musicales. Lecturas de etnomusicología. Madrid: Trotta.

Dewey, J. (1934). El arte como experiencia. Barcelona: Paidós.

Eisner, E. (2002). El arte y la creación de la mente. El papel de las artes visuales en la transformación de la conciencia. Barcelona: Paidós.

Finnegan, R. (2002). ¿Por qué estudiar la música? Reflexiones de una antropóloga desde el campo. Trans-Revista transcultural de música, 6, 1-18. Extraído el 15 de junio, 2013, de http://www.sibetrans.com/trans/a224/por-que-estudiar-la-musicareflexiones-de-una-antropologa-desde-el-campo.

Flores Rodrigo, S. (2008). Música y adolescencia. La música popular actual como herramienta en la educación musical. Madrid: INJUVE. Extraído el 10 de junio, 2013, de http://www.injuve.es/.

Graeme, F. (2003). Arte, educación y diversidad cultural. Barcelona: Paidós.

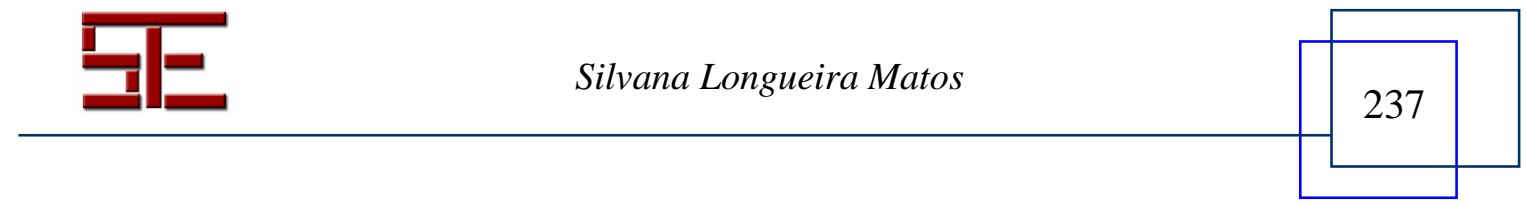




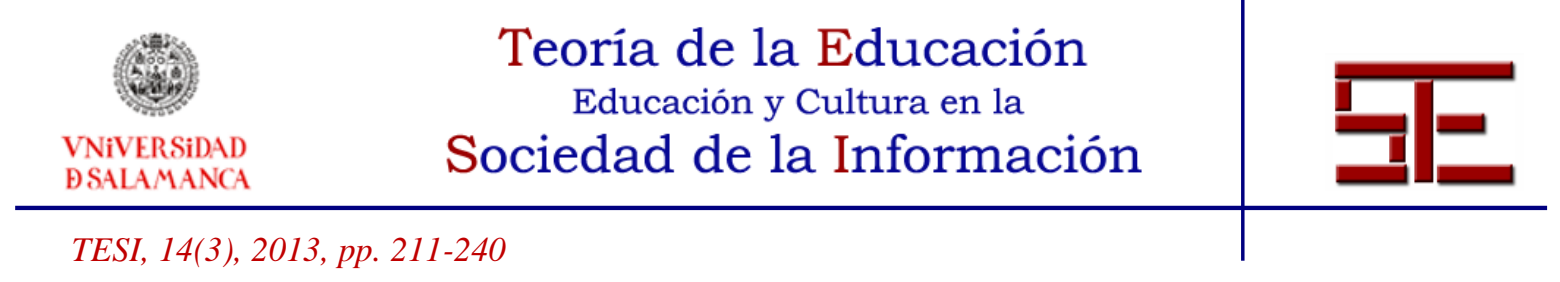

Hargreaves, D. J. y North, A. D. (1999). The functions of music in everyday life: Redefinng the social in music psychlogy. Psychology of Music, 27 (1), 71-83.

Hennion, A. (2010). Gustos musicales: de una sociología de la mediación a una pragmática del gusto. Comunicar, XVII (34), 25-33.

INE (2008). El ocio en cifras. Extraído el 8 de junio, 2013, de http://www.ine.es/revistas/cifraine/0408.pdf.

INE (2011). Encuesta sobre Equipamiento y Uso de Tecnologías de la Información y Comunicación en los hogares. Extraído el 10 de abril, 2013, de http://www.ine.es/jaxi/menu.do?type=pcaxis \&path=/t25/p450/a2011/\&file=pcaxis

Jiménez, J. (2002). Teoría del arte. Madrid: Anaya.

Ley Orgánica 2/2006 de 3 de mayo de Educación (LOE). BOE del 4 de mayo de 2006.

Longueira, S. (2012). Construyendo la convivencia a través de la música. Desarrollo cívico y educación "por” la música. En J. M. Touriñán, Desarrollo cívico, sentido intercultural de la educación y convivencia cualificada y especificada. A Coruña: Netbiblo.

Marchán, S. (1994). Del arte conceptual al arte del concepto. Madrid: Akal.

Marco, T. (2002). Pensamiento musical y siglo XX. Madrid: Fundación Autor.

Martínez Berriel, S. (2011). El género de la música en la cultura global. TRANS-Revista transcultural de música, 15. Extraído el 15 de junio, 2013, de http://www.sibetrans.com/trans/.

MCU (2011). Cuenta Satélite de la Cultura. Avance de resultados 2000-2009. Extraído el 8 de abril, 2013, de http://www.mcu.es/estadisticas/docs/CSCE/avance_resultados_csce-2011.pdf.

Merriam, A. P. (1964). The antropology of Music. Evanston: Northwestern University Press.

Ministerio de Educación (2012). Recursos económicos. Gasto público en educación. Año 2010. Extraído el 15 de junio, 2013, de http://www.mecd.gob.es/servicios-alciudadano-mecd/estadisticas/educacion/recursos-economicos/gastopublico/2010.html.

Ministerio de Educación (2013). Datos y cifras. Curso escolar 2012-2013. Estraído el 15 de junio, 2013, de http:/www.mecd.gob.es/dctm/ministerio/horizontales/estadisticas/indicadorespublicaciones/datos-cifras/datos-y-cifras-2012-2013web.pdf?documentId=0901e72b81416daf.

Ors, C. d' (1980). Aproximación al arte de hoy. Arbor. Ciencia, pensamiento y cultura, 96 (415), 67-79.

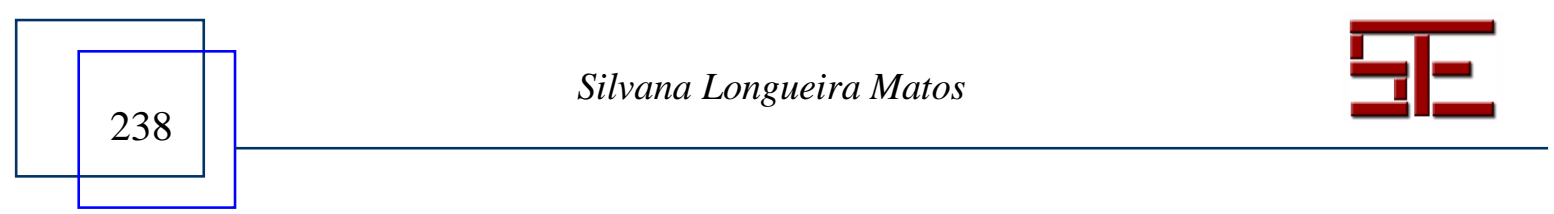




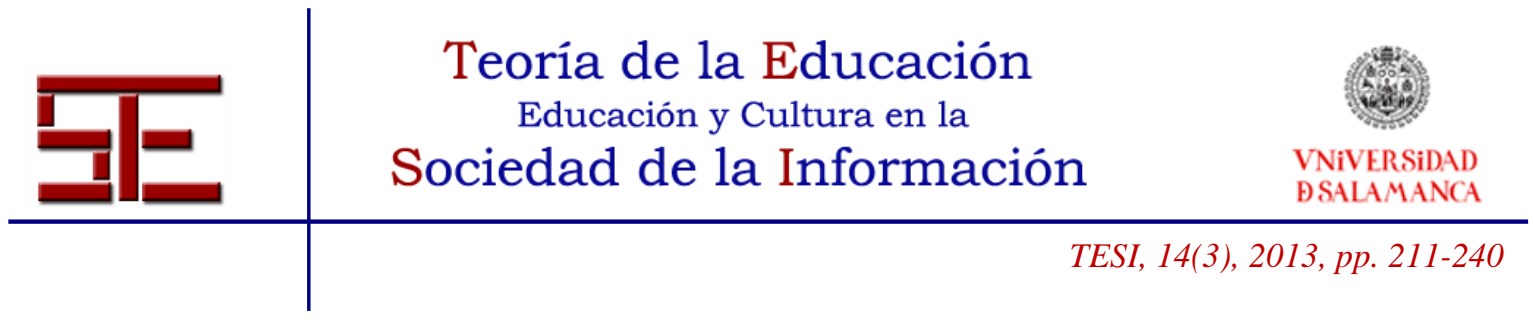

Pelinski, R. (2000). Invitación a la etnomusicología. Quince fragmentos y un tango. Madrid: Akal.

Real Decreto 1513/2006, de 7 de diciembre, por el que se establecen las enseñanzas mínimas para este nivel. $B O E$ del 8 de diciembre.

Real Decreto 1630/2006, de 29 de diciembre, por el que se establecen las enseñanzas mínimas del segundo ciclo de Educación infantil. BOE del 4 de enero.

Real Decreto 1631/2006, de 29 de diciembre por el que se establecen las enseñanzas mínimas correspondientes a la educación secundaria obligatoria. $B O E$ del 5 de enero.

SEP (2004). La educación en contextos multiculturales. Diversidad e identidad. Actas del XIII Congreso Nacional de Pedagogía. Valencia: Sociedad Española de Pedagogía.

SGAE (2011). Anuario SGAE de las Artes escénicas, Musicales y audiovisuales 2011. Madrid: Fundación Autor/SGAE. Extraído el 10 de mayo, 2013, de http://www.anuariossgae.com/anuario2011/home.html.

Small, C. (1989). Música, sociedad, educación. Un examen de la función de la música en las culturas occidentales, orientales y africanas, que estudia su influencia sobre la sociedad y sus usos en la educación. Madrid: Alianza.

Smart Planet (Productor) (2011). Redes. El sistema educativo es anacrónico. RTVE, 13 de marzo. Extraído el 10 de junio, 2013, de http://www.rtve.es/television/20110304/redes-sistema-educativo-anacronico/413516.shtml.

Touriñán, J. M. (2006). Educación en valores y experiencia axiológica: el sentido patrimonial de la educación. Revista Española de Pedagogía, 234, 227-248.

Touriñán, J. M. (Dir.) (2008). Educación en valores, educación intercultural y formación para la convivencia pacífica. A Coruña: Netbiblo.

Touriñán López, J. M. (Dir.) (2010). Artes y educación. Fundamentos de Pedagogía mesoaxiológica. A Coruña: Netbiblo.

Touriñán, J. M. (2011). Claves para aproximarse a la educación artística en el sistema educativo: educación "por" las artes y educación "para" un arte. Revista ESE, estudios sobre educación, (21, diciembre), 61-81.

Touriñán, J. M. y Longueira, S. (2009). Formación de criterio a favor de la música como ámbito de educación, Bordón, 61 (1), 43-60.

Touriñán, J. M. y Longueira, S. (2010a). La música como ámbito de educación. La educación musical como educación, como educación artística y como educación

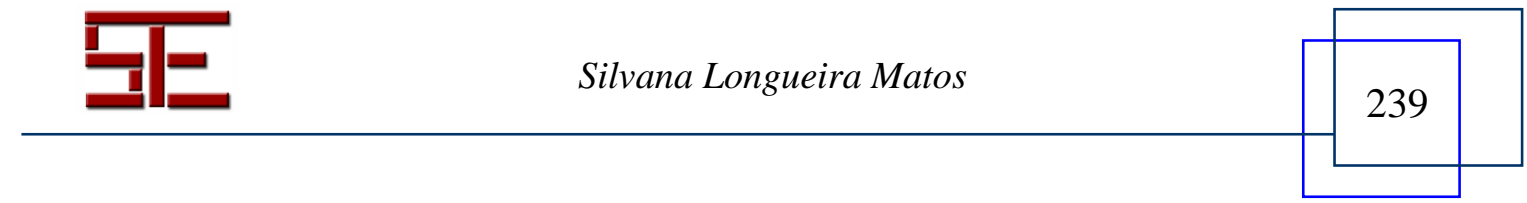




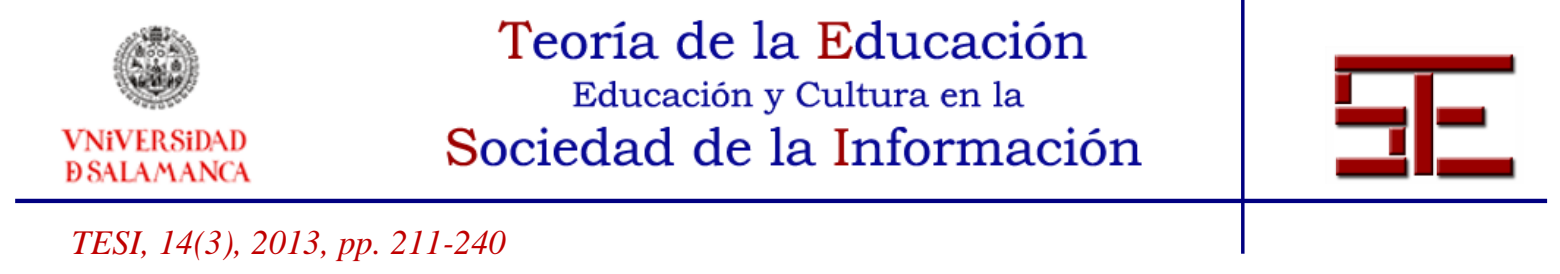

profesional y vocacional, en J. M. Touriñán (Coord.) Artes y educación. Fundamentos de pedagogía mesoaxiológica, A Coruña: Netbiblo, pp. 197-238.

Touriñán, J. M. y Longueira, S. (2010b). La música como ámbito de educación. Educación "por" la música y educación "para" la música. Revista Interuniversitaria de Teoría de la Educación, 22 (2), 151-181.

Touriñán, J. M. y Sáez, R. (2012). Teoría de la educación, metodología y focalizaciones. La mirada pedagógica. A Coruña: Netbiblo.

UNESCO (1982). Declaración de México sobre las políticas culturales. Conferencia mundial sobre políticas culturales. México DF, 26 de julio al 6 de agosto de 1982. Extraído el 8 de abril, 2013, de http://portal.unesco.org/culture/es/.

UNESCO (2005a). Declaración de Bogotá sobre educación artística. Bogotá, 30 de noviembre. Extraído el 8 de abril, 2013, de http://portal.unesco.org/culture/en/files/29876/12651903953813BA79A.pdf/813BA79A.pdf.

UNESCO (2005b). Convención sobre la protección y la promoción de la diversidad de las expresiones culturales. París: UNESCO. Extraído el 10 de junio, 2013, de http://unesdoc.unesco.org/images/0014/001429/142919s.pdf.

UNESCO (2010). Segunda Conferencia Mundial sobre la Educación Artística. Seúl, 2528 de mayo. Extraído el 10 de mayo, 2013, de http://portal.unesco.org/.

Unión Europea (2008). Tratado de funcionamiento de la Unión Europea. Diario Oficial de la Unión Europea de 9 de mayo de 2008 (2008/C 115/47-199). Extraído el 10 de junio, 2013, de http://eur-lex.europa.eu/.

Para citar el presente artículo puede utilizar la siguiente referencia:

Longueira Matos, S. (2013). Los retos educativos en la sociedad del conocimiento. Aproximación a las aportaciones desde el ámbito de la educación musical. Revista Teoría de la Educación: Educación y Cultura en la Sociedad de la Información. 14(3), 211240 [Fecha de consulta: dd/mm/aaaa].

http://campus.usal.es/ revistas_trabajo/index.php/revistatesi/article/view/11358/11775

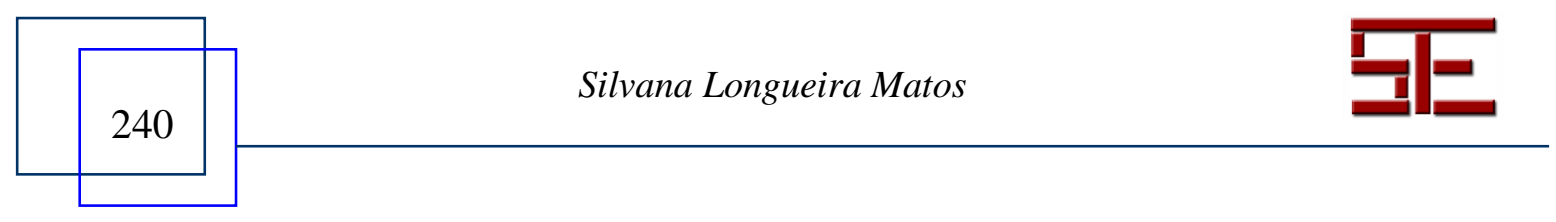

